\title{
Understanding the rapid summer warming and changes in temperature extremes since the mid-1990s over Western Europe
}

\author{
Buwen Dong ${ }^{1} \cdot$ Rowan T. Sutton $^{1} \cdot$ Len Shaffrey $^{1}$
}

Received: 8 January 2016 / Accepted: 27 April 2016 / Published online: 5 May 2016

(C) The Author(s) 2016. This article is published with open access at Springerlink.com

\begin{abstract}
Analysis of observations indicates that there was a rapid increase in summer (June-August) mean surface air temperature (SAT) since the mid-1990s over Western Europe. Accompanying this rapid warming are significant increases in summer mean daily maximum temperature, daily minimum temperature, annual hottest day temperature and warmest night temperature, and an increase in frequency of summer days and tropical nights, while the change in the diurnal temperature range (DTR) is small. This study focuses on understanding causes of the rapid summer warming and associated temperature extreme changes. A set of experiments using the atmospheric component of the state-of-the-art HadGEM3 global climate model have been carried out to quantify relative roles of changes in sea surface temperature (SST)/sea ice extent (SIE), anthropogenic greenhouse gases (GHGs), and anthropogenic aerosols (AAer). Results indicate that the model forced by changes in all forcings reproduces many of the observed changes since the mid-1990s over Western Europe. Changes in SST/SIE explain $62.2 \pm 13.0 \%$ of the area averaged seasonal mean warming signal over Western Europe, with the remaining $37.8 \pm 13.6 \%$ of the warming explained by the direct impact of changes in GHGs and AAer. Results further indicate that the direct impact of the reduction of AAer precursor emissions over Europe, mainly through aerosol-radiation interaction with additional contributions from aerosol-cloud interaction and coupled atmosphere-land surface feedbacks, is a key factor for increases in annual hottest day temperature and in
\end{abstract}

Buwen Dong

B.Dong@reading.ac.uk

1 National Centre for Atmospheric Science, Department of Meteorology, University of Reading, Reading, UK frequency of summer days. It explains $45.5 \pm 17.6 \%$ and $40.9 \pm 18.4 \%$ of area averaged signals for these temperature extremes. The direct impact of the reduction of AAer precursor emissions over Europe acts to increase DTR locally, but the change in DTR is countered by the direct impact of GHGs forcing. In the next few decades, greenhouse gas concentrations will continue to rise and AAer precursor emissions over Europe and North America will continue to decline. Our results suggest that the changes in summer seasonal mean SAT and temperature extremes over Western Europe since the mid-1990s are most likely to be sustained or amplified in the near term, unless other factors intervene.

Keywords Surface air temperature $\cdot$ Temperature extremes · Western Europe - Atmospheric general circulation model $\cdot$ Greenhouse gas $\cdot$ Anthropogenic aerosol

\section{Introduction}

European summer climate exhibits variability on a wide range of timescales. Understanding the nature and drivers of this variability is an essential step in developing robust climate predictions and risk assessments. In the last few decades, Europe has warmed not only faster than the global average, but also faster than expected from anthropogenic greenhouse gas increases (Ruckstuhl et al. 2008; Philipona et al. 2009; van Oldenborgh et al. 2009). With the warming, Europe experienced record-breaking heat waves and extreme temperatures that imposed disastrous impacts on individuals, and society (Stott et al. 2004; Fischer and Schär 2010; Barriopedro et al. 2011; Christidis et al. 2011, 2012; Hegerl et al. 2011; Rahmstorf and Coumou 2011; Hoerling et al. 2012; Schubert et al. 
2014; Sillmann et al. 2014; Vautard et al. 2007, 2013). Such climate events are often accompanied by prominent anomalies in atmospheric circulation and precipitation, as well as in the conditions of the nearby land and ocean surfaces. The extreme 2003 European and 2010 Russian heat waves have been shown to be associated with blocking regimes. However, Barnes et al. (2014) showed that there is no increasing trend of summer blocking frequency over Western Europe based on three different reanalysis data sets, suggesting that the link between rapid surface warming and changes in blocking frequency on the decadal time scale is weak.

The impacts of temperature extremes have highlighted the urgency of improved understanding of their physical causes and to what extent they are a manifestation of a warming world (e.g., Dole et al. 2011; Trenberth and Fasullo 2012; Otto et al. 2012; Christidis et al. 2014; Perkins 2015). A number of studies have investigated the factors contributing to such extreme events (Schär et al. 2004; Otto et al. 2012; Hanlon et al. 2013; Christidis et al. 2014) and how extremes will change in response to anthropogenic forcings (Kim et al. 2013; Lindvall and Svensson 2014; Cattiaux et al. 2015; Vavrus et al. 2015). These factors include the role of soil-atmosphere feedbacks during the hot summers. In summer, dry soil induces fewer clouds, presumably through reduced upward latent heat fluxes, which in turn increases the amount of incident solar energy at the surface and further enhances heat fluxes and the ratio of sensible over latent heat fluxes. This causes a positive feedback to soil drying (Vautard et al. 2007; Fischer and Schär 2010; Seneviratne et al. 2010; Fischer et al. 2012; Kim et al. 2013; Boé and Terray 2014; Lindvall and Svensson 2014; Miralles et al. 2014; Cattiaux et al. 2015; Whan et al. 2015), highlighting the importance of local landatmosphere interactions in driving the regional temperature extremes. Other factors include SST anomalies affecting heat waves in Western Europe through boundary forcing induced large scale circulation (e.g., Cassou et al. 2005; Sutton and Hodson 2005; Black and Sutton 2007; DellaMarta et al. 2007; Carril et al. 2008; Feudale and Shukla 2011a, b; Kamae et al. 2014).

Due to air quality legislation, AAer precursor emissions in Europe and North America have continuously decreased since the 1980s (Smith et al. 2011; Kühn et al. 2014). This decrease in AAer precursor emissions and the accompanied increase in downward surface solar radiation (solar "brightening") is considered as the likely cause of the rapid warming over Western Europe (Wild 2009, 2012; Folini and Wild 2011; Nabat et al. 2014). However, it is still not clear to what extent the rapid warming over Western Europe is a result of a fast land-atmosphere response to the direct impact of changes in GHGs and AAer and to what extent the warming is mediated by the SST changes induced by these forcings. In particular, the relative roles of these forcing factors on the temperature extremes have not been investigated.

The main aims of this work are to determine the relative roles of changes in: (i) SST/SIE, (ii) GHGs, and (iii) AAer forcings in shaping the changes in the summer mean SAT and temperature extremes since the mid-1990s over Western Europe. This will be achieved by performing a set of experiments using the atmospheric component of the stateof-the-art HadGEM3 global climate model. In this paper, we do not address the role of land use change (e.g., Christidis et al. 2013). The structure of the paper is as follows. Section 2 describes observed changes since the mid-1990s. In Sect. 3, the model and experiments are described briefly. Section 4 presents simulated changes in response to different forcings. Section 5 elucidates the physical processes for the responses. Conclusions are in Sect. 6.

\section{Observed changes since the mid-1990s over Western Europe}

\subsection{Observational data sets}

The monthly mean SAT data sets used are the University of Delaware (UD) land SAT (1901-2010) (Legates and Willmott 1990a, b), the CRU TS3.21 data sets (1901-2013) on a $0.5^{\circ} \times 0.5^{\circ}$ grid (Harris et al. 2014), the NASA GISS Surface Temperature Analysis (GISTEMP) (1880-2013) on a $2^{\circ} \times 2^{\circ}$ grid (Hansen et al. 2010), and the HadCRUT4 data set (Morice et al. 2012). Temperature extreme indices used are daily maximum temperature $\left(\mathrm{T}_{\max }\right)$, daily minimum temperature $\left(\mathrm{T}_{\min }\right)$, and annual hottest day temperature $\left(\mathrm{TX}_{\mathrm{x}}\right)$, warmest night temperature $\left(\mathrm{TN}_{\mathrm{x}}\right)$, the diurnal temperature range (DTR), the frequency of summer days (SU, annual number of days when $\mathrm{T}_{\max }>25^{\circ} \mathrm{C}$ ), and tropical nights (TR, annual number of days when $\mathrm{T}_{\min }>20^{\circ} \mathrm{C}$ ). $\mathrm{T}_{\max }, \mathrm{T}_{\min }$, and DTR are based on CRU TS3.21 data sets. $\mathrm{TX}_{\mathrm{x}}, \mathrm{TN}_{\mathrm{x}}, \mathrm{SU}$, and TR are based on HadEX2 data set (Donat et al. 2013) and the E-OBS gridded data set (Haylock et al. 2008). Monthly mean SSTs used are HadISST on a $1^{\circ} \times 1^{\circ}$ grid (Rayner et al. 2003). Monthly mean variables of NCEP/NCAR reanalysis (1979-2013) (Kalnay et al. 1996) and monthly sea level pressures of HadSLP2 date (Allan and Ansell 2006) are also used.

\subsection{Observed changes in summer mean temperature and temperature extremes}

Illustrated in Fig. 1 are time series of the area averaged summer (June to August, JJA) SAT, and summer or annual temperature extreme anomalies over Western Europe $\left(35^{\circ} \mathrm{N}-70^{\circ} \mathrm{N}, 10^{\circ} \mathrm{W}-40^{\circ} \mathrm{E}\right.$, land only) relative to the climatology over the time series expanding period. One of 
(a) SAT indices (35N-70N, 10W-40E) in JJA

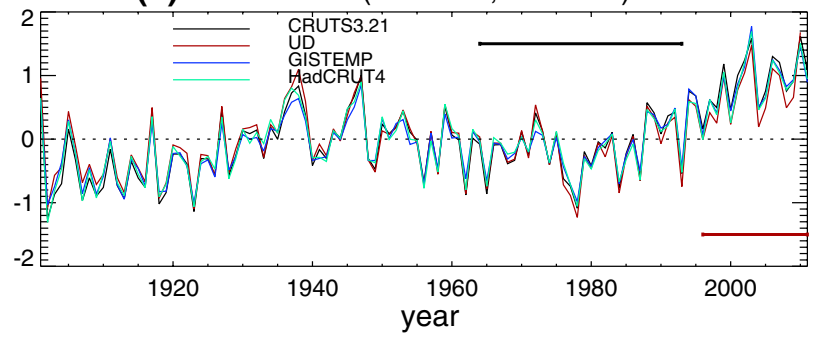

(b) Tmax, Tmin, and DTR in JJA (CRUT3.21)

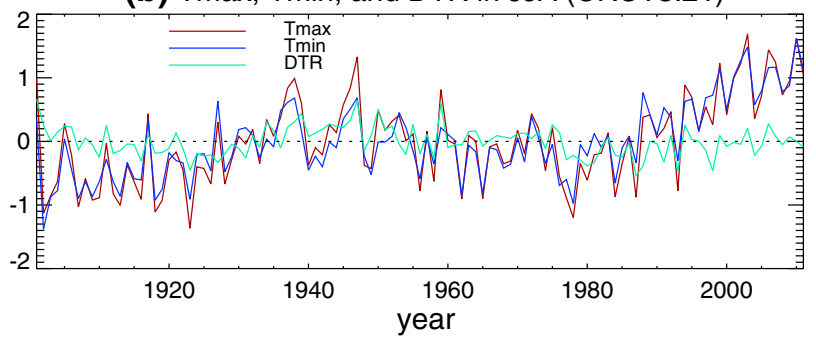

(c) Extreme temperature indices TXx and TNx

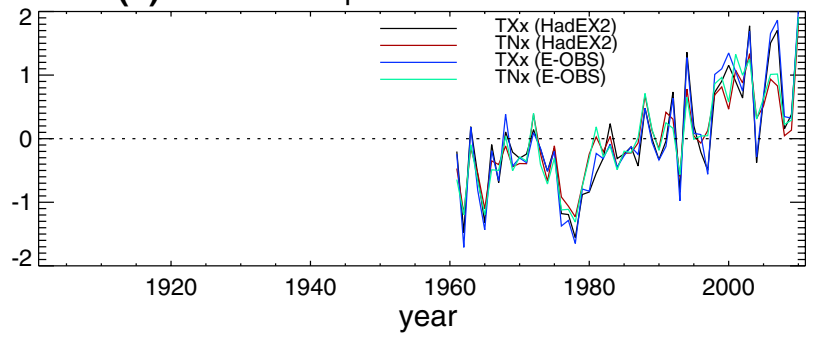

(d) Summer days and Tropical nights

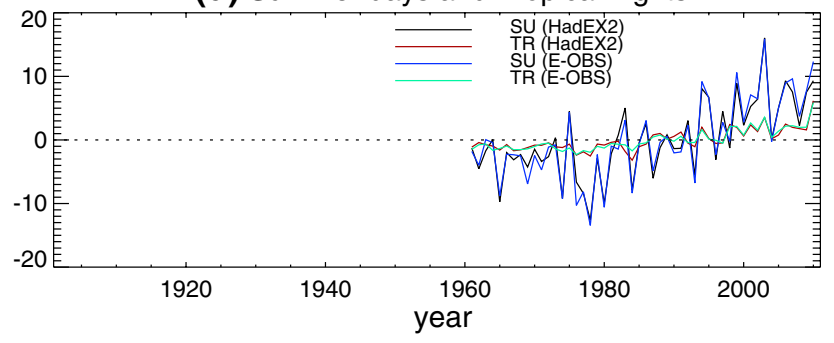

Fig. 1 Time series of summer (JJA) or annual mean anomalies relative to the climatology (mean of the whole period) averaged over Western Europe $\left(35^{\circ} \mathrm{N}-70^{\circ} \mathrm{N}, 10^{\circ} \mathrm{W}-40^{\circ} \mathrm{E}\right.$, red box in Fig. 2a). a SAT $\left({ }^{\circ} \mathrm{C}\right), \mathbf{b ~ T}_{\max }, \mathrm{T}_{\min }$, and DTR $\left({ }^{\circ} \mathrm{C}\right)$, $\mathbf{c}$ annual hottest day temperature $\left(\mathrm{TX}_{\mathrm{x}}\right)$ and warmest night temperature $\left(\mathrm{TN}_{\mathrm{x}}\right)\left({ }^{\circ} \mathrm{C}\right)$, and $\mathbf{d}$ number of summer days (SU) and tropical nights (TR) (day year ${ }^{-1}$ ). $\mathrm{TX}_{\mathrm{x}}$, $\mathrm{TN}_{\mathrm{x}}, \mathrm{SU}$, and TR based on two data sets of HadEX2 and E-OBS are shown. Black and red range bars indicate the earlier period of 19641993 and the recent period of 1996-2011

most important features is the abrupt surface warming since the mid-1990s (Fig. 1a). The change in SAT during the recent 16 years (1996-2011) relative to the early period 1964-1993 ranges from 0.93 to $1.10^{\circ} \mathrm{C}$ from four data sets, consistent with previous studies (Ruckstuhl et al. 2008; Philipona et al. 2009; van Oldenborgh et al. 2009).

The rapid summer mean warming over Western Europe was also accompanied by changes in temperature extremes.
The time evolutions of area averaged temperature extremes (Fig. 1b-d) show a rapid increase in summer mean $\mathrm{T}_{\max }$, $\mathrm{T}_{\min }, \mathrm{TX}_{\mathrm{x}}$ and $\mathrm{TN}_{\mathrm{x}}$ over Western Europe. The change in DTR, however, is small. Analysis also shows a rapid increase in the frequency of SU, and TR over Western Europe since the mid-1990s. SU and TR have increased by 8 and 3 days respectively over the last 16 years relative to 30 year mean (1964-1993).

The spatial patterns of changes in SAT and temperature extremes between the two periods are illustrated in Fig. 2. Most important changes are the increase in summer mean SAT, $\mathrm{T}_{\max }$ and $\mathrm{T}_{\min }$ over most regions with a magnitude of about $0.8-1.2{ }^{\circ} \mathrm{C}$ over Europe although there are some spatial variations (Fig. 2a-c). The changes in SAT, $\mathrm{T}_{\max }$, and $\mathrm{T}_{\min }$ show a large increase over Central and Southern Europe while the changes in DTR are relatively small despite a weak increase over Central Europe of about 0.2$0.6{ }^{\circ} \mathrm{C}$ (Fig. 2d). The changes in $\mathrm{TX}_{\mathrm{x}}$ and $\mathrm{TN}_{\mathrm{x}}$ (Fig. 2e, f) between the two periods show a localized maximum (about 1.8 and $1.2{ }^{\circ} \mathrm{C}$ respectively) over Central Europe and indicate that the increase in $\mathrm{TX}_{\mathrm{x}}$ is larger than the increase in $\mathrm{TN}_{\mathrm{x}}$. The changes in frequency of SU and TR (Fig. 2g, h) also show an increase with a local maximum around the Mediterranean region of about 12-16 and 2-8 days respectively, suggesting larger increase in the number of hot days than warm nights.

What has caused these rapid changes in both summer mean SAT and temperature extremes over Western Europe since the mid-1990s? By performing a set of numerical experiments using the atmospheric component of the stateof-the-art HadGEM3 global climate model with different forcings we will investigate the drivers for those observed changes since the mid-1990s.

\section{Model and model experiments}

\subsection{Model and model experiments}

Relative to the baseline period of 1964-1993, there are changes in potential drivers of climate from the mid-1990s (Fig. 3). SSTs have warmed (Fig. 3a). There are significant increases in anthropogenic GHG concentrations (11\% increase in $\mathrm{CO}_{2}, 18 \%$ increase in $\mathrm{CH}_{4}$, and $6 \%$ increase in $\mathrm{N}_{2} \mathrm{O}$ ) and significant changes in AAer precursor emissions (Lamarque et al. 2010) with European and North American sulphur dioxide emissions decreased while Asian emissions increased (Fig. 3b).

Climate model experiments have been carried out to identify the roles of changes in SST/SIE, GHG and AAer forcings in the recent changes in summer mean temperature and temperature extremes over Western Europe. The model used is the atmosphere configuration of the Met 
Fig. 2 Spatial patterns of differences of some temperature extremes between the recent period of 1996-2011 and the earlier period of 1964-1993. a SAT, b $\mathrm{T}_{\max }, \mathbf{c} \mathrm{T}_{\min }, \mathbf{d}$ DTR, e $\mathrm{TX}_{\mathrm{x}}, \mathbf{f} \mathrm{TN}_{\mathrm{x}}, \mathbf{g} \mathrm{SU}$, and $\mathbf{h} \mathrm{TR}$. SAT, $\mathrm{T}_{\max }, \mathrm{T}_{\min }, \mathrm{DTR}, \mathrm{TX}_{\mathrm{x}}$, and $\mathrm{TN}_{\mathrm{x}}$ are in ${ }^{\circ} \mathrm{C}$. SU and TR are in day year ${ }^{-1}$. The thick red box in (a) highlights Western Europe (a) SAT change in JJA (CRUTS3.21)

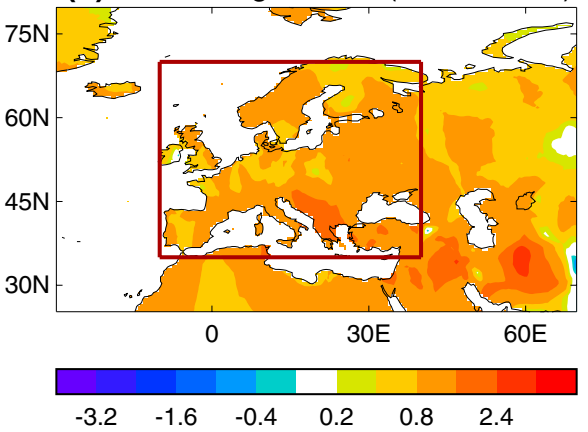

(b) Tmax change in JJA (CRUTS3.21)

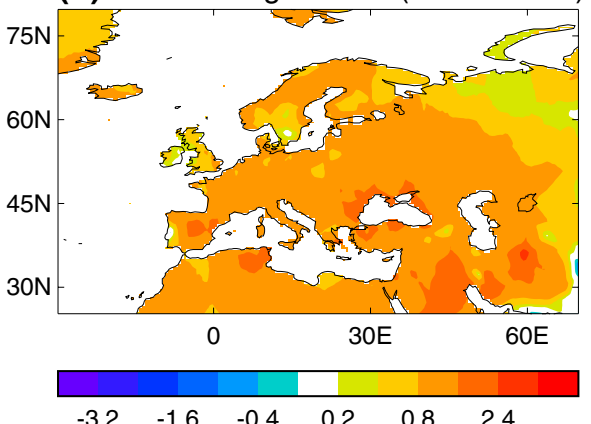

(d) DTR change in JJA (CRUTS3.21)

(c) Tmin change in JJA (CRUTS3.21)
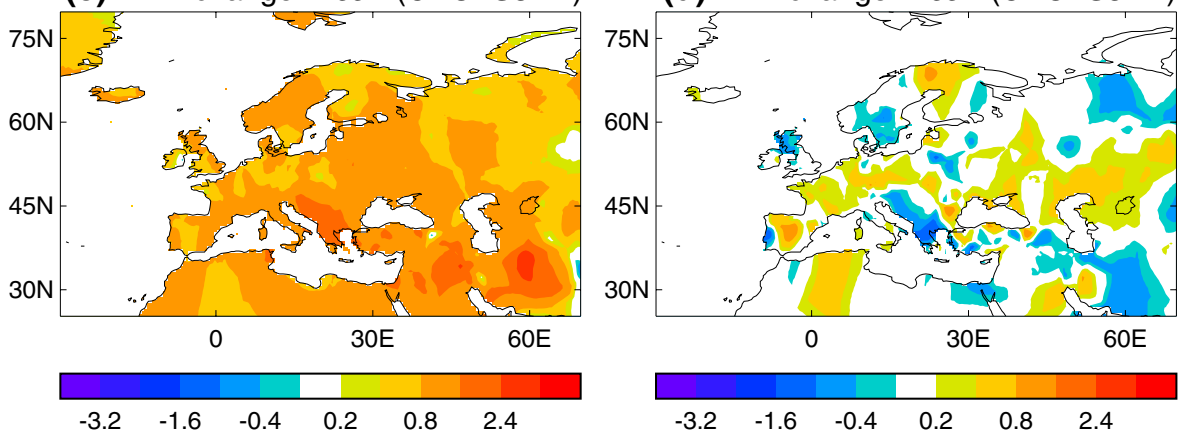

(e) Change in TXX (HadEX2)

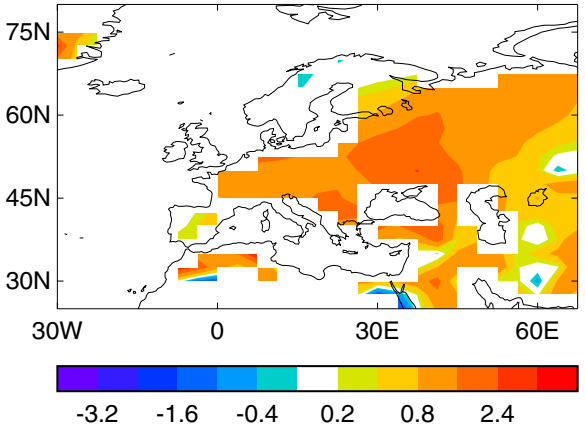

(g) Change in Summer days (HadEX2)

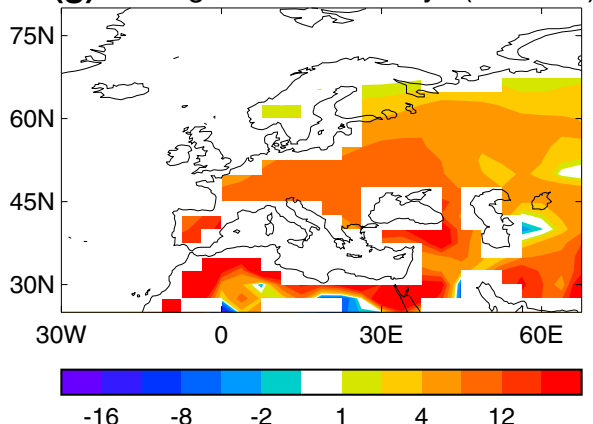

(f) Change in TNx (HadEX2)

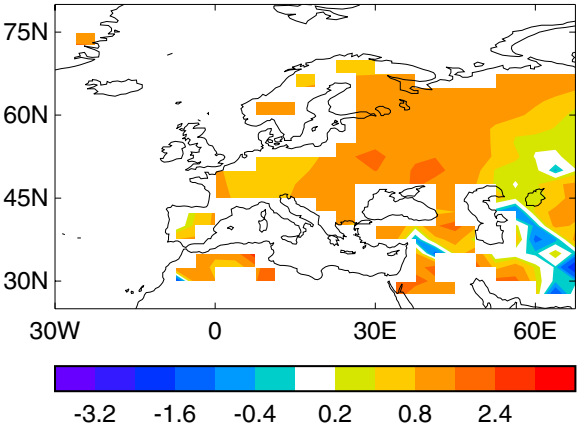

(h) Change in Tropical night (HadEX2)

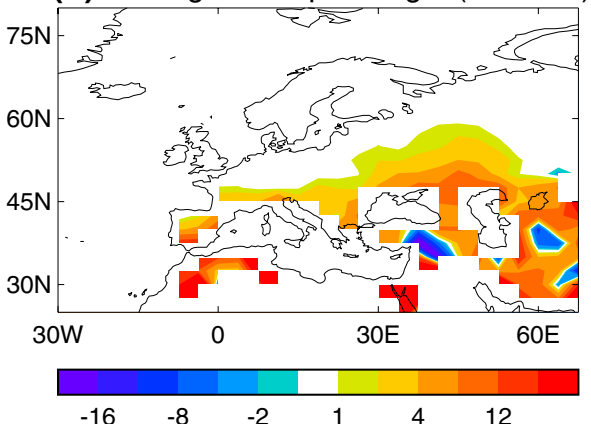

Office Hadley Centre Global Environment Model version 3 (HadGEM3-A) (Hewitt et al. 2011), with a resolution of $1.875^{\circ}$ longitude by $1.25^{\circ}$ latitude and 85 levels in the vertical. The model includes an interactive tropospheric chemistry scheme and eight aerosol species (ammonium sulphate, mineral dust, fossil-fuel black carbon, fossil-fuel organic carbon, biomass-burning, ammonium nitrate, sea-salt, and secondary organic aerosols from biogenic emissions). Both aerosol-radiation and aerosol-cloud interactions are considered (Bellouin et al. 2013). Data sets required by the tropospheric aerosol scheme in the model are emissions of sulphur dioxide $\left(\mathrm{SO}_{2}\right)$, land-based 
(a) SST in JJA (1996to2011-1964to1993, HadISST)

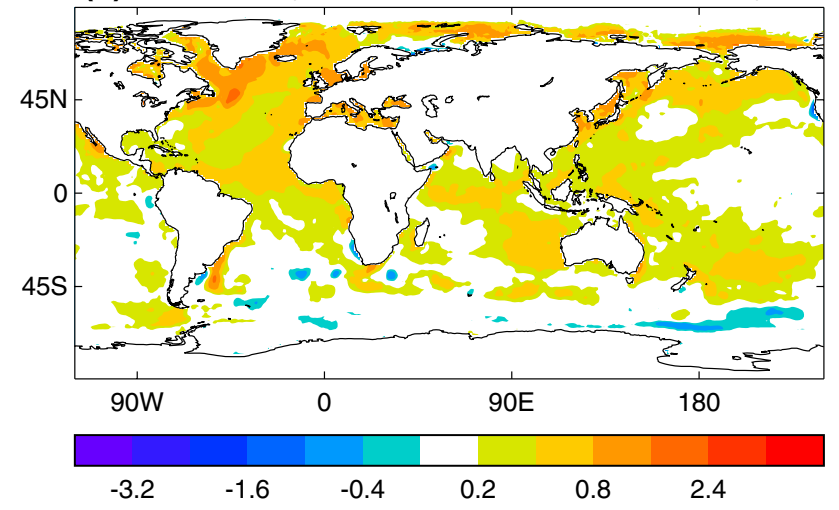

(b) Annual sulphur dioxide(1996to2010-1970to1993)

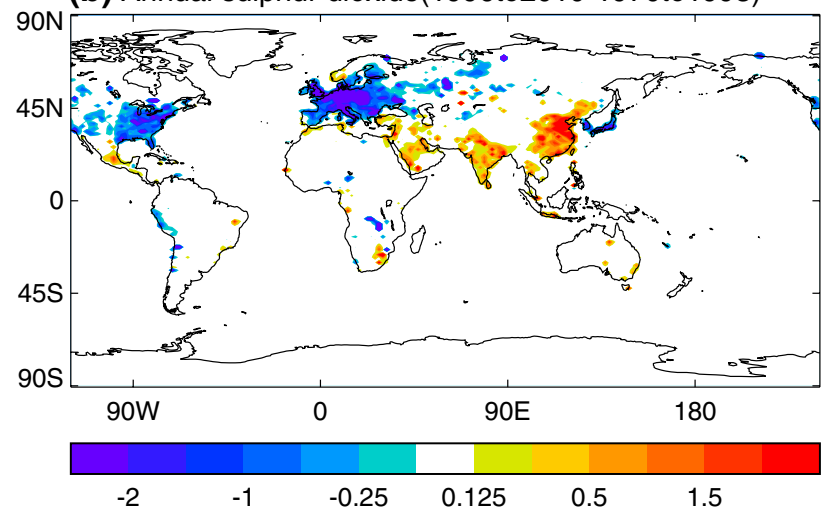

Fig. 3 a Global SST changes in JJA $\left({ }^{\circ} \mathrm{C}\right)$ based on HadISST between two periods and $\mathbf{b}$ annual mean sulphur dioxide emissions $\left(\mathrm{g} \mathrm{m}^{-2} \mathrm{yr}^{-1}\right.$ ) difference between 1996-2010 and 1970-1993

dimethyl sulphide (DMS), ammonia $\left(\mathrm{NH}_{3}\right)$, and primary black and organic carbon aerosols from fossil fuel combustion and biomass burning. A set of experiments (each for either 32 or 27 years) has been carried out to identify the roles of changes in: (i) SST/SIE, (ii) anthropogenic GHGs, and (iii) AAer forcings in shaping the changes of the summer mean SAT and temperature extremes over Western Europe. The experiments are: CONTROL forced by the early period (1964-1993) SST/SIE, GHGs and AAer; ALL forced by the recent period (1996-2011) SST/SIE, GHGs and AAer; SSTGHG forced by the recent period SST/SIE and GHGs, but the early period AAer; SSTONLY forced by the recent period SST/SIE, but the early period GHGs and AAer. No attempt has yet been made to separate the anthropogenic contribution to SST/SIE change in these experiments. Detailed experiments are documented in Table 1 and they are the same experiments as those investigated in Dong and Sutton (2015) for the recent recovery of the Sahel rainfall. The last 25 years of each experiment are analysed and the response to a particular forcing is estimated by the difference between a pair of experiments that include and exclude that forcing. Statistical significance of the summer mean or annual changes and the $90 \%$ confidence intervals of the area averaged changes over Western Europe in both observations and model experiments are assessed using a two tailed Student $t$ test.

\subsection{Model climatology}

In this section, climatological features of the CONTROL experiment are compared with observed features (Fig. 4). Figure $4 \mathrm{a}-\mathrm{c}$ show the SAT based on NCEP reanalysis (Kalnay et al. 1996), sea level pressure (SLP) of HadSLP2 (Allan and Ansell 2006). $850 \mathrm{hPa}$ wind distribution (NCEP reanalysis), and observed rainfall based on GPCP (Adler et al. 2003). Figure $4 \mathrm{~d}-\mathrm{f}$ show the corresponding model climatologies.

Observations show a strong meridional SAT gradients around $45^{\circ} \mathrm{N}$ over East North Atlantic and Western Europe (Fig. $4 \mathrm{a}-\mathrm{c}$ ). The circulation is characterized by the subtropical anticyclone over subtropical North Atlantic and with a ridge extending eastward over the Mediterranean region (Fig. 4b). Associated with circulation are strong westerlies across the UK into Western Europe and northwesterlies over the east part of the Mediterranean region. Observed precipitation indicates a band of large precipitation of $>2.0 \mathrm{~mm} \mathrm{day}{ }^{-1}$ extending from North Atlantic into Western Europe with precipitation over the Iberian Peninsula

Table 1 Summary of numerical experiments

Experiments Boundary conditions

CONTROL Monthly climatological sea surface temperature (SST) and sea ice extent (SIE) averaged over the period 1964 to 1993 , using HadISST (Rayner et al. 2003) with greenhouse gas (GHG) concentrations set at mean values over the same period, and anthropogenic aerosol (AAer) precursor emissions (Lamarque et al. 2010) at mean values over the period 1970-1993

ALL Monthly climatological SST/SIE averaged over the period of 1996 to 2011, with GHG concentrations set at mean values over the period 1996-2009, and AAer precursor emissions at mean values over the period 1996-2010

SSTGHG Monthly climatological SST/SIE averaged over the period of 1996 to 2011, with GHG concentrations set at mean values over the period 1996-2009, but with AAer precursor emissions at mean values over the period 1970-1993

SSTONLY Monthly climatological SST/SIE averaged over the period of 1996 to 2011, with GHG concentrations and AAer precursor emissions the same in the CONTROL experiment 
(a) SAT in JJA (NCEP)

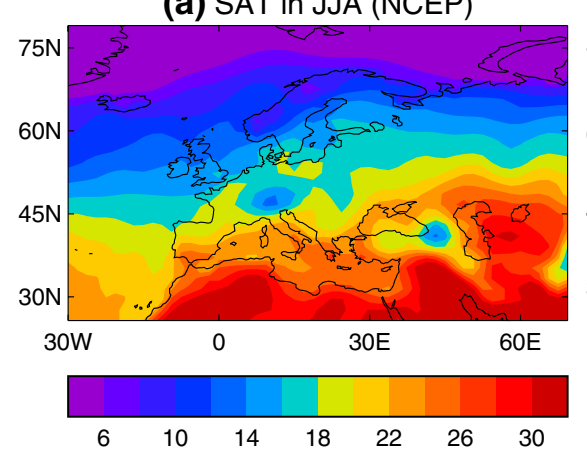

(d) SAT in JJA (Model)

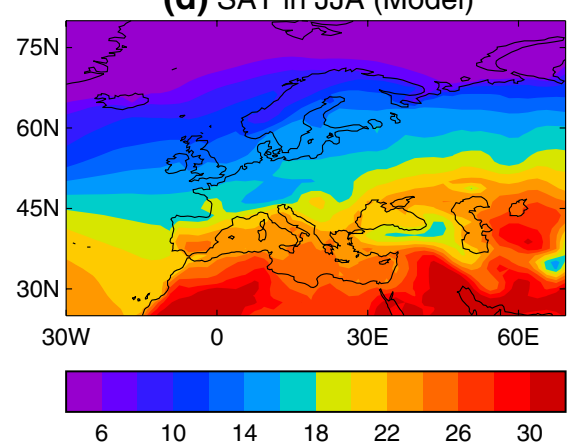

(b) $850 \mathrm{hPa}$ wind and SLP

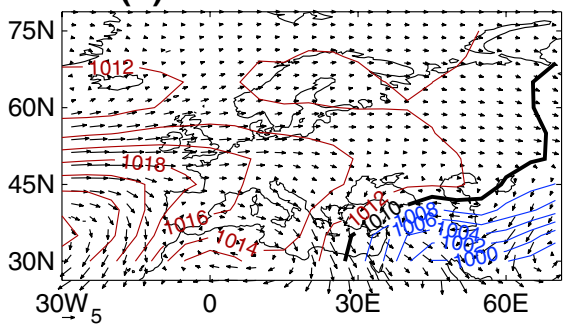

(e) $850 \mathrm{hPa}$ wind and SLP (Model)

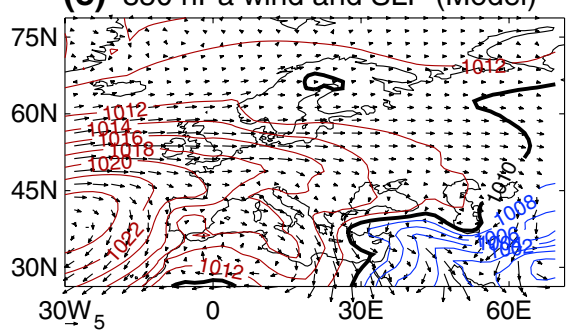

(c) Precipitation in JJA (GPCP)
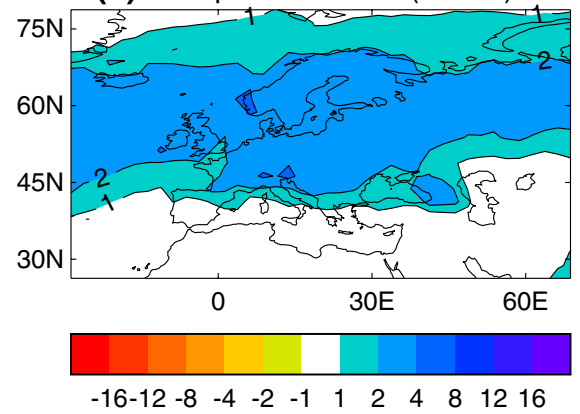

(f) Precipitation in JJA (Model)

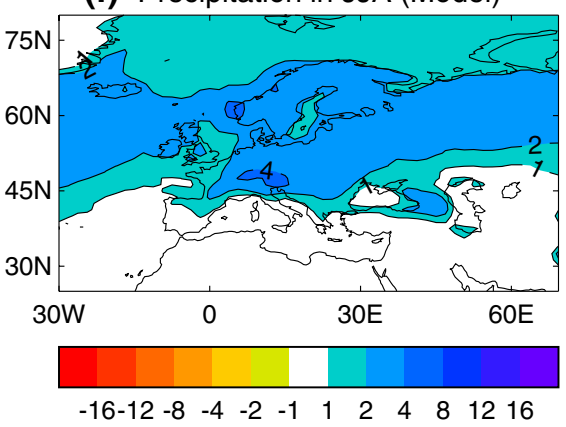

Fig. 4 The spatial patterns of JJA climatology for SAT $\left({ }^{\circ} \mathrm{C}\right)$, SLP $(\mathrm{hPa})$ and $850 \mathrm{hPa}$ winds $\left(\mathrm{m} \mathrm{s}^{-1}\right)$ and precipitation $\left(\mathrm{mm} \mathrm{day}^{-1}\right)$ in observations $(\mathbf{a}-\mathbf{c})$ and in the model CONTROL experiment $(\mathbf{d}-\mathbf{f})$

and over the Mediterranean Sea being $<1.0 \mathrm{~mm} \mathrm{day}^{-1}$. The model reproduces the spatial patterns of the summer climate fairly well over the North Atlantic and the European sector (Fig. 4d-f), suggesting that it is an appropriate tool for the investigation of the response of regional climate to different forcings.

\section{Model simulated responses to different forcings}

The spatial patterns of changes in summer mean SAT in response to different forcings are shown in Fig. 5. The model experiment forced by changes in SST/SIE and anthropogenic GHG and AAer forcings (Fig. 5a), relative to the CONTROL, reproduces many of the observed changes over Europe (Fig. 2a). Responses to the different forcings indicate that the warming is predominately due to changes in SST/SIE (Fig. 5b) with the direct impact in AAer changes playing an important role for warming over Central and Southern Europe. The direct impact in GHG changes induce more localized warming over Northwestern Europe (Fig. 5c). Changes in SAT in response to different forcings show large spatial variations across Europe, implying the role of changes in regional circulation and land surface feedbacks for the simulated response in summer mean SAT. The detailed mechanisms of responses to different forcings will be discussed in Sect. 5.

The responses of summer seasonal mean daily $\mathrm{T}_{\max }$, $\mathrm{T}_{\min }$, and DTR to different forcings are illustrated in Fig. 6. In response to changes in all forcings, the model results show an increase in both $\mathrm{T}_{\max }$ and $\mathrm{T}_{\text {min }}$ over Europe with changes in $\mathrm{T}_{\max }$ being large over Southern and Central Europe, while $\mathrm{T}_{\min }$ changes show a more uniform increase (Fig. 6a, b). As a result, DTR changes show an increase over Southern and Central Europe (Fig. 6c). Comparison with observed changes (Fig. 2d) indicate that the enhancement of DTR over Southern and Central Europe is overestimated in the model simulations. Changes in SST/SIE lead to an increase in both $\mathrm{T}_{\max }$ and $\mathrm{T}_{\text {min }}$ over a large part of Europe with a similar magnitude except for around the Mediterranean coast where $T_{\max }$ changes are larger than $\mathrm{T}_{\min }$ changes. As a result, DTR change is small except for a weak increase around the Mediterranean coast (Fig. 6f). The direct impact of GHG changes leads to an increase in both $\mathrm{T}_{\max }$ and $\mathrm{T}_{\min }$ with large increase over Northern Europe of similar magnitude (Fig. $6 \mathrm{~g}, \mathrm{~h}$ ). As a result, the direct impact of GHG changes induced DTR change is weak over most regions of Western Europe, except for a decrease over Southwestern Europe (Fig. 6i) where $\mathrm{T}_{\max }$ shows a decrease related to an increase in cloud cover (Sect. 5.2). In contrast, the direct impact of AAer changes 
Fig. 5 Spatial patterns of summer mean (JJA) SAT $\left({ }^{\circ} \mathrm{C}\right)$ changes. a Response forced by changes in SST/SIE, GHG concentrations, and AAer precursor emissions (ALL-CONTROL), b response to changes in SST/ SIE (SSTONLY-CONTROL), c response to the changes in GHG concentrations (SSTGHGSSTONLY), and d response to changes in AAer precursor emissions (ALL-SSTGHG). Thick black lines highlight regions where the changes are statistically significant at the $90 \%$ confidence level using a two-tailed Student $t$ test (a) SAT change in JJA (All)

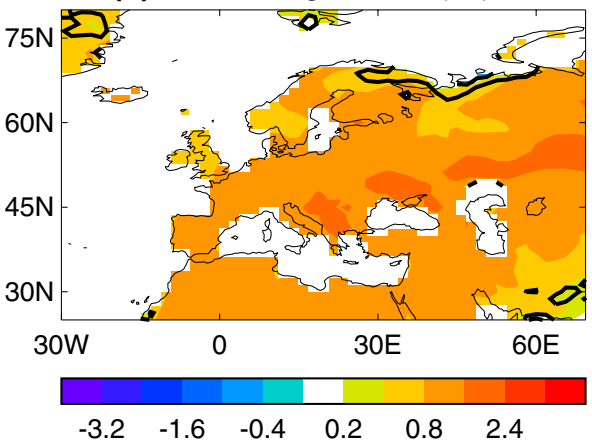

(c) SAT change in JJA (GHG)

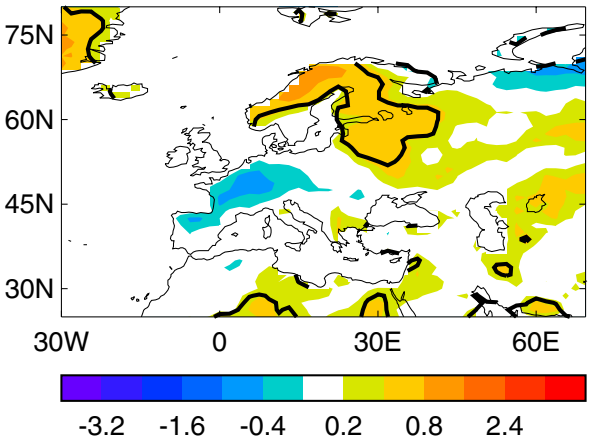

(b) SAT change in JJA (SST)

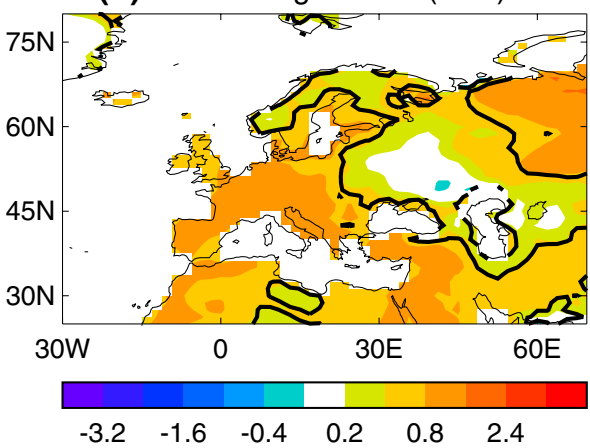

(d) SAT change in JJA (aerosols)

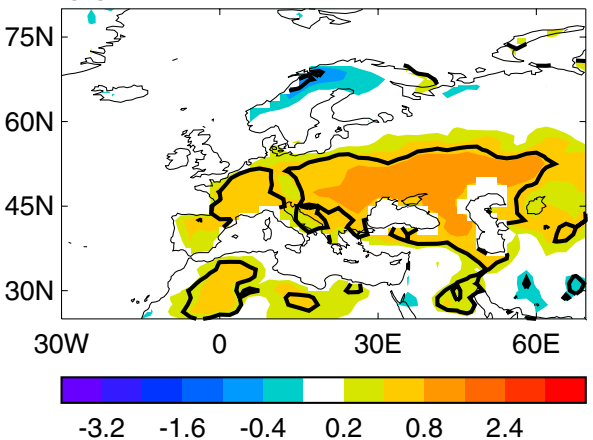

through aerosol-radiation and aerosol-cloud interactions leads to an increase in $\mathrm{T}_{\max }$ over a latitude band of $40^{\circ}-$ $50^{\circ} \mathrm{N}$ over Europe while AAer induced changes in $\mathrm{T}_{\min }$ are smaller (Fig. 6j, k). As a result, AAer changes induce significant increases in DTR over Europe (Fig. 61). Comparing responses of DTR to different forcings indicates that the increase of DTR in all forcing experiment over Western Europe is predominately due to the direct impact from AAer changes (Fig. 6c, f, i, j).

The spatial patterns of responses in $\mathrm{TX}_{\mathrm{x}}$ and $\mathrm{TN}_{\mathrm{x}}$ are illustrated in Fig. 7 and changes in frequencies of summer days and tropical nights are in Fig. 8. Figure 7 demonstrates the important role of changes in AAer for changes in $\mathrm{TX}_{\mathrm{x}}$ over Western Europe while the changes in SST/SIE plays the dominant role for change in $\mathrm{TN}_{\mathrm{x}}$. Figure 8 shows an equally important role of changes in SST/SIE and AAer for the increase in frequency of summer days, while the increase in frequency of tropical nights is predominantly due to the change in SST/SIE.

Some area averaged summer or annual temperature extreme indices over Western Europe for both observations and model simulations are illustrated in Fig. 9. There is good agreement between the model forced by changes in all forcings and observed changes in summer seasonal mean $\mathrm{SAT}, \mathrm{T}_{\max }$, and $\mathrm{T}_{\min }$ (Fig. 9a). In response to changes in all forcings, the model simulates an area-averaged summer mean SAT change of $1.16 \pm 0.21{ }^{\circ} \mathrm{C}$ over Western Europe, which is very close to observed change of 0.93 to $1.10{ }^{\circ} \mathrm{C}$ although differs in spatial pattern. The changes in SST/ SIE explain $62.2 \pm 13.0 \%$ of the area-averaged SAT signal, with the $37.8 \pm 13.6 \%$ explained by the direct impact of changes in GHGs and AAer (Fig. 9b). Both changes in SST/SIE and AAer lead to an increase in $T_{\max }$, while the increase in $\mathrm{T}_{\min }$ is predominantly due to the change in SST/ SIE (Fig. 9b). The direct impact of AAer changes act to increase DTR, but change in DTR is countered by direct impact of GHG forcing. However, DTR change in response to all forcings is overestimated by the model. Results further suggest that the direct impact of AAer changes plays an important role in the increase in $\mathrm{TX}_{\mathrm{x}}$ and the increase in frequency of summer days (explaining $45.5 \pm 17.6 \%$ and $40.9 \pm 18.4 \%$ of the signal in the response to changes in all forcings). The increases in $\mathrm{TN}_{\mathrm{x}}$ and in the frequency of tropical nights are mainly mediated through the warming of the ocean (Fig. 9b).

\section{Physical processes for the model simulated responses to different forcings}

In this section, the physical processes responsible for the model responses to different forcings are elucidated in detail by focusing on changes in the surface energy components and related variables over land. 
(a) Tmax change in JJA (All)

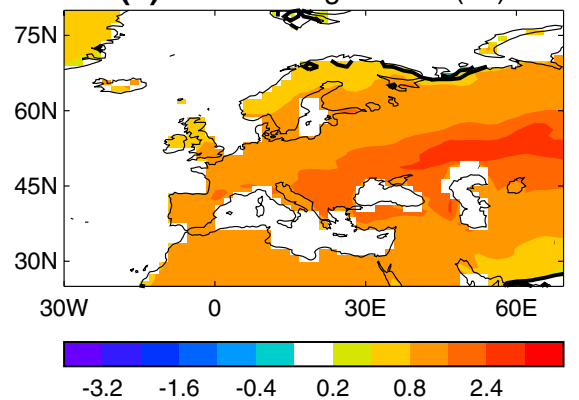

(d) Tmax change in JJA (SST)

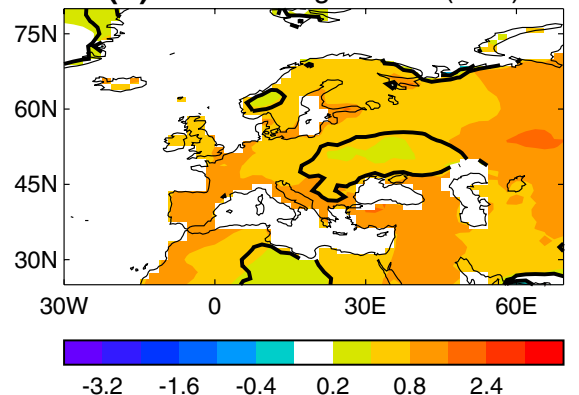

(g) Tmax change in JJA (GHG)

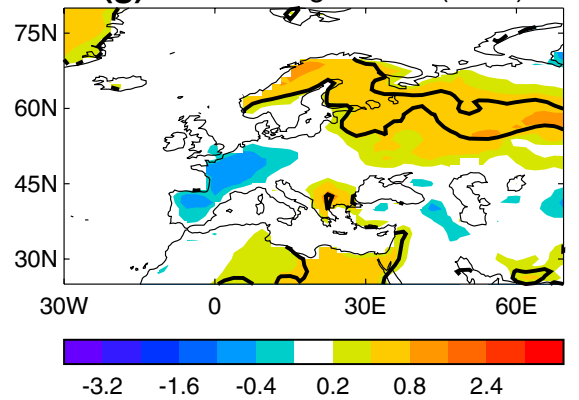

(j) Tmax change in JJA (aerosols)

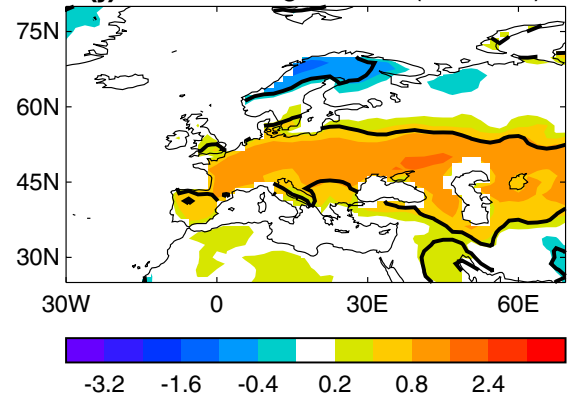

(b) Tmin change in JJA (All)

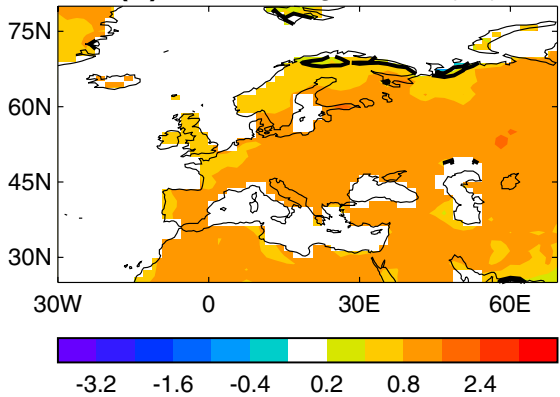

(e) Tmin change in JJA (SST)

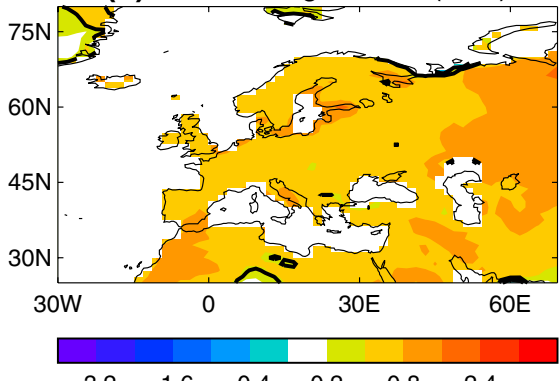

(h) Tmin change in JJA (GHG)

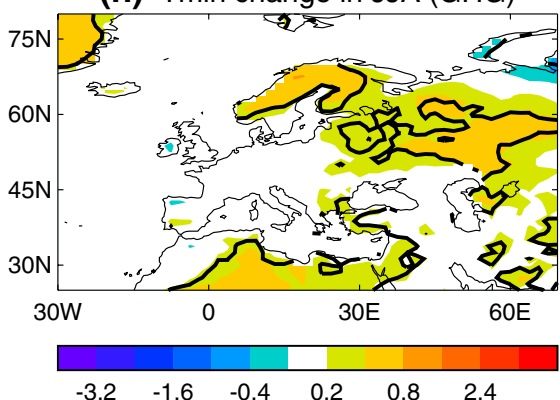

(k) Tmin change in JJA (aerosols)

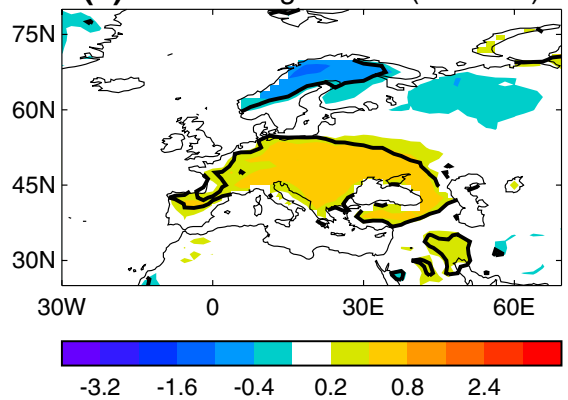

(c) DTR change in JJA (All)

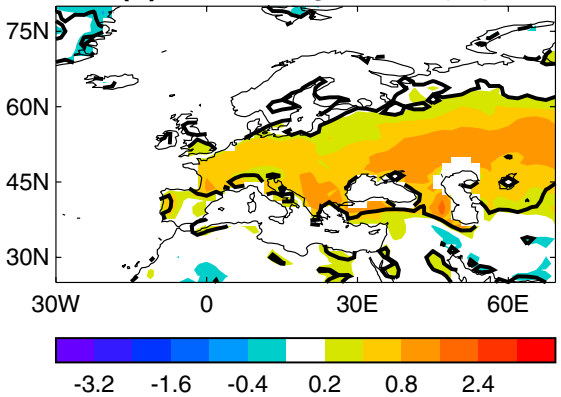

(f) DTR change in JJA (SST)

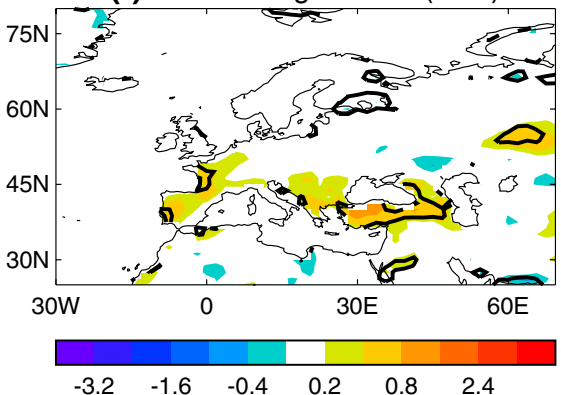

(i) DTR change in JJA (GHG)

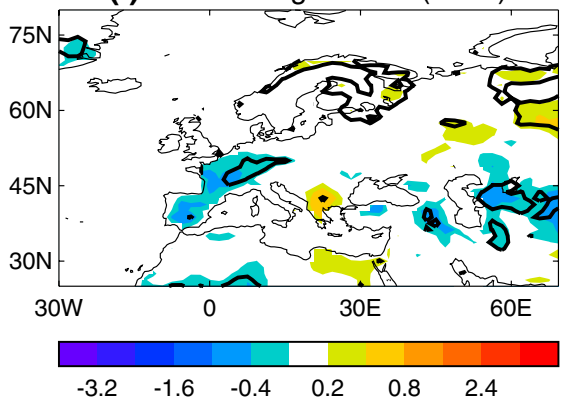

(I) DTR change in JJA (aerosols)

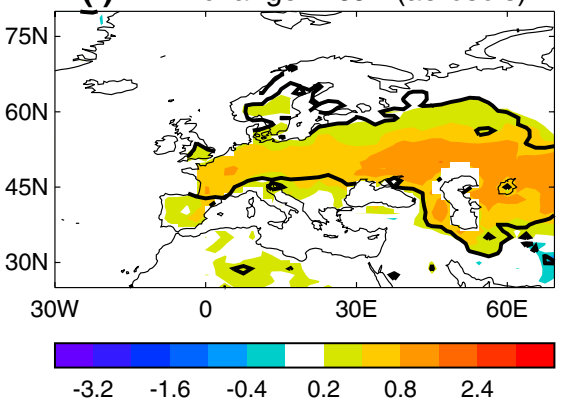

Fig. 6 Spatial patterns of summer mean responses for $\mathrm{T}_{\max }$ (left column), $\mathrm{T}_{\min }$ (middle column), and DTR (right column). Unit is in ${ }^{\circ} \mathrm{C}$. a-c Response forced by changes in SST/SIE, GHG concentrations, and AAer precursor emissions (ALL-CONTROL), d-f response to changes in SST/SIE (SSTONLY-CONTROL), $\mathbf{g}-\mathbf{i}$ response to the changes in GHG concentrations (SSTGHG-SSTONLY), and $\mathbf{j}-\mathbf{l}$ response to changes in AAer precursor emissions (ALL-SSTGHG). Thick black lines highlight regions where the changes are statistically significant at the $90 \%$ confidence level using a two-tailed Student $t$ test 
Fig. 7 Spatial patterns of responses for annual hottest day temperature (left column) and warmest night temperature (right). Unit is in ${ }^{\circ} \mathbf{C} . \mathbf{a}, \mathbf{b}$

Response forced by changes in SST/SIE, GHG concentrations, and AAer precursor emissions (ALL-CONTROL), $\mathbf{c}, \mathbf{d}$ response to changes in SST/SIE (SSTONLY-CONTROL), e, $\mathbf{f}$ response to the changes in GHG concentrations (SSTGHG-

SSTONLY), and $\mathbf{g}, \mathbf{h}$ response to changes in AAer precursor emissions (ALL-SSTGHG). Thick black lines highlight regions where the changes are statistically significant at the $90 \%$ confidence level using a two-tailed Student $t$ test (a) TXx change in (All)

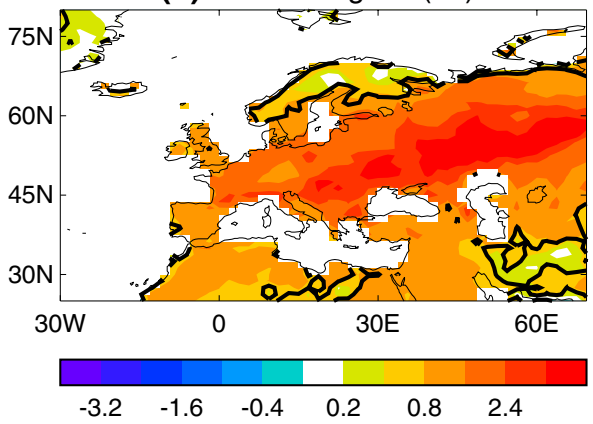

(c) TXx change in (SST)

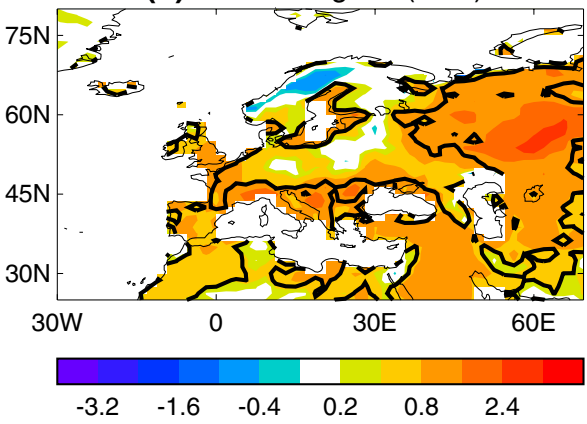

(e) TXx change in (GHG)

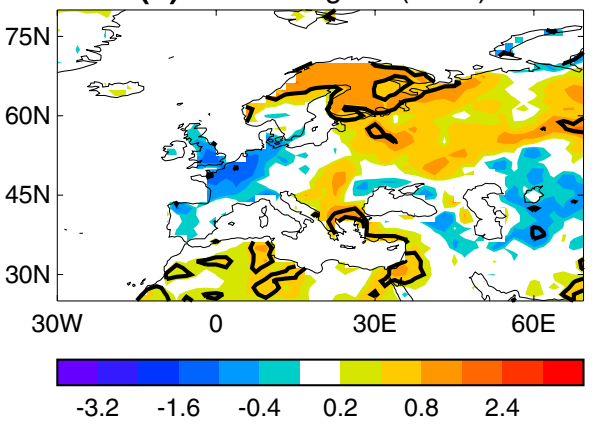

(g) TXx change in (aerosols)

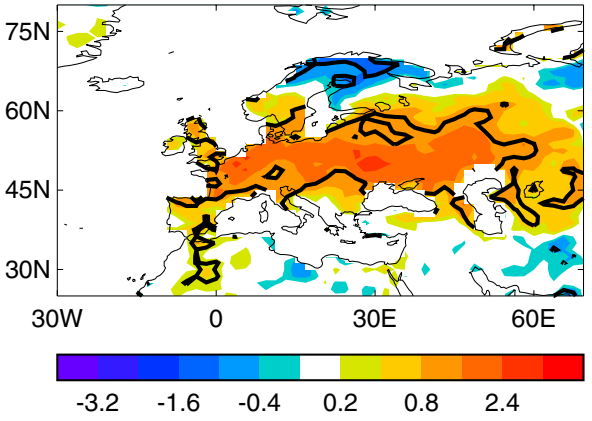

(b) TNx change in (All)

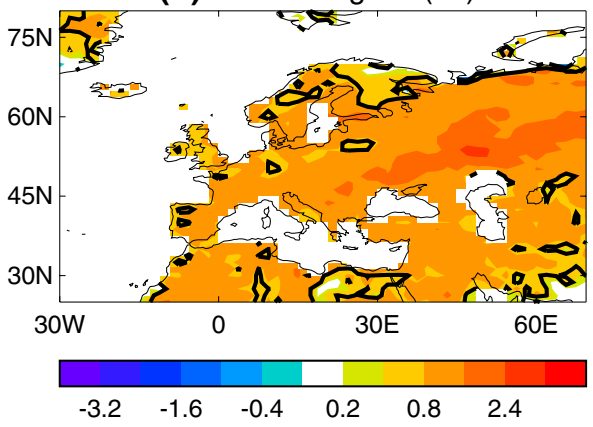

(d) TNx change in (SST)

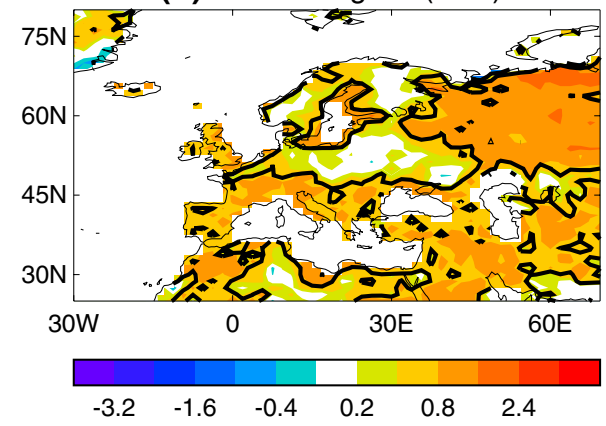

(f) $T N x$ change in (GHG)

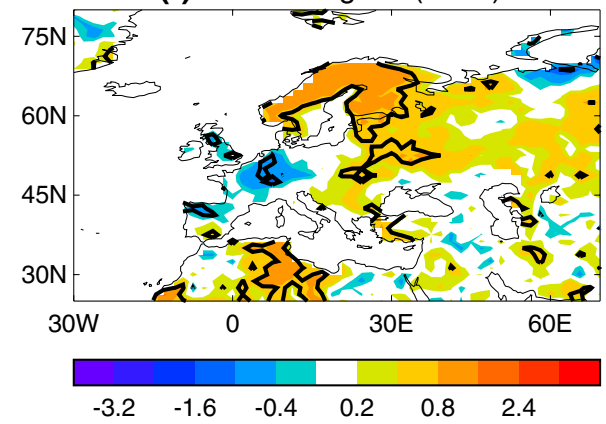

(h) TNx change in (aerosols)

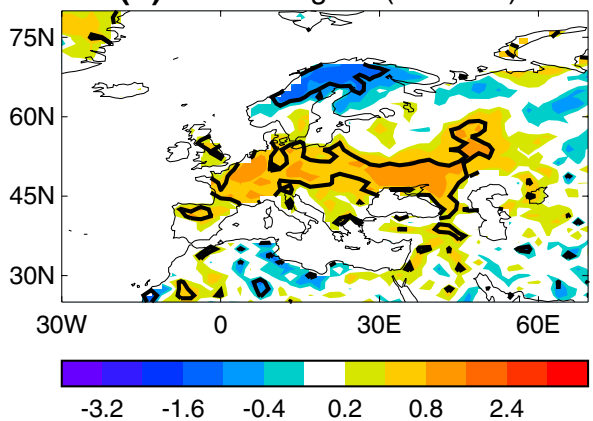

\subsection{Response to changes in SST/SIE}

The spatial patterns of summer mean changes for the components of surface energy balance and related variables induced by changes in SST/SIE forcing are illustrated in Fig. 10. In response to changes SST/SIE, the specific humidity over land increases (Fig. 10a). Under the hypothesis that atmospheric moisture over European land comes to a large extent from oceanic evaporation through atmospheric transport, continental specific humidity is expected to increase more in line with temperature change over oceans (e.g., Boé and Terray 2014). As the warming is 
Fig. 8 Spatial patterns of responses for summer days ( $\mathrm{SU}$, left) and tropical nights (TR, right). Unit is in day year ${ }^{-1}$. a, b Response forced by changes in SST/SIE, GHG concentrations, and AAer precursor emissions (ALL-CONTROL), $\mathbf{c}, \mathbf{d}$ response to changes in SST/SIE (SSTONLY-CONTROL), $, \mathbf{e}, \mathbf{f}$ response to the changes in GHG concentrations (SSTGHGSSTONLY), and $\mathbf{g}, \mathbf{h}$ response to changes in AAer precursor emissions (ALL-SSTGHG). Thick black lines highlight regions where the changes are statistically significant at the $90 \%$ confidence level using a two-tailed Student $t$ test (a) Summer days change in (All)

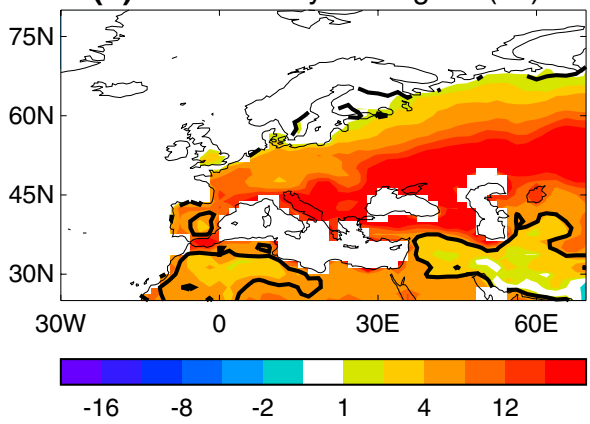

(c) Summer days change in (SST)

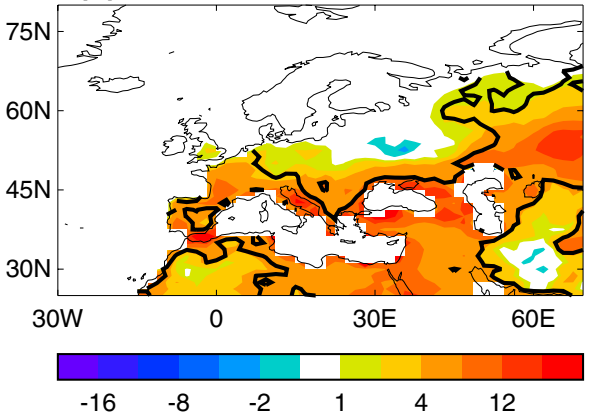

(e) Summer days change in (GHG)

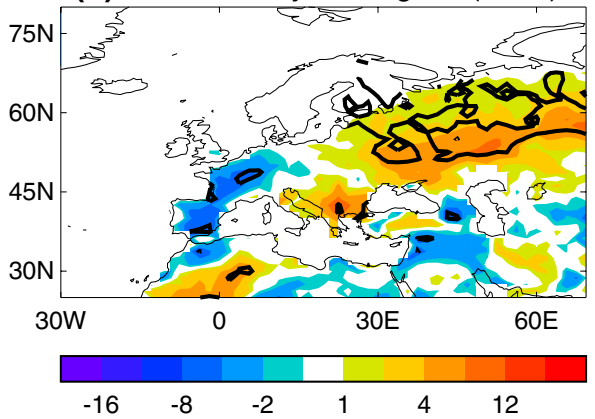

(g) Summer days change in (aerosols)

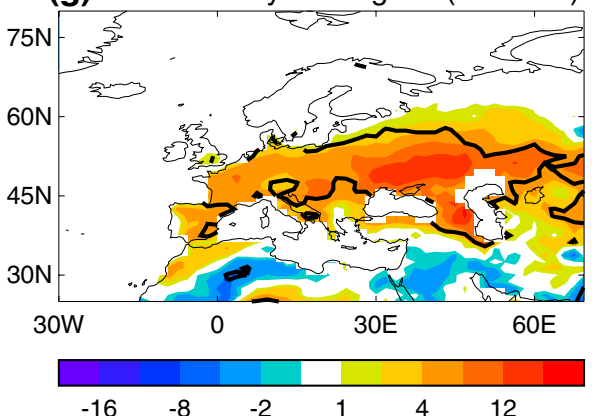

(b) Tropical night change in (All)

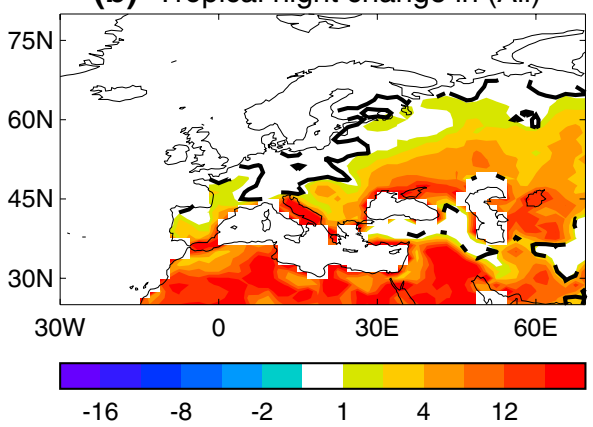

(d) Tropical night change in (SST)

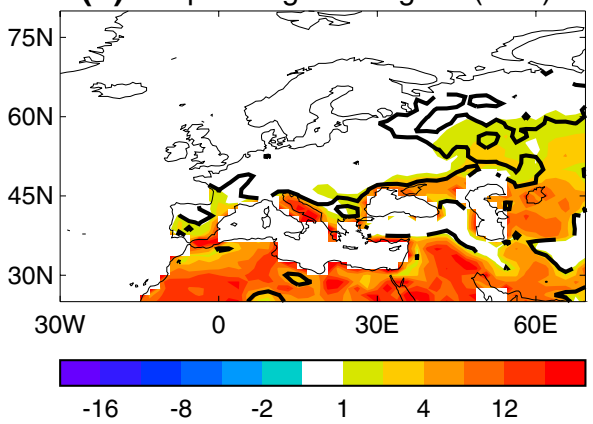

(f) Tropical night change in (GHG)

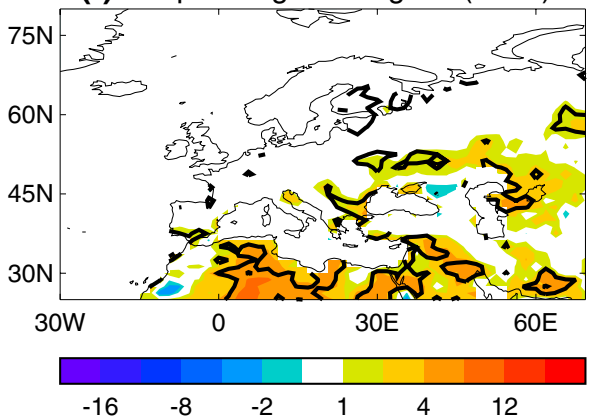

(h) Tropical night change in (aerosols)

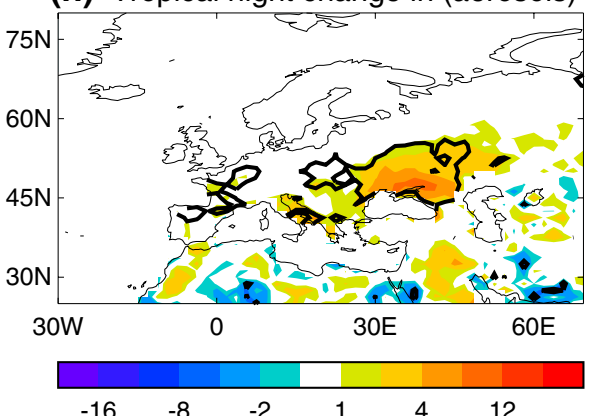

generally larger over land in the response to the changes in SST/SIE (Figs. 3a, 5b), specific humidity over land will increase less than specific humidity at saturation which increases with the continental surface temperature following the Clausius-Clapeyron relationship. This leads to a decrease in relative humidity (Fig. 10c) (e.g., Rowell and Jones 2006; Dong et al. 2009). With decreasing relative humidity, saturation becomes harder to reach, the lifted condensation level increases, which then leads to a decrease in continental cloud cover (Fig. 10d) (e.g., Dong et al. 
(a) Area $(35 \mathrm{~N}-70 \mathrm{~N}, 10 \mathrm{~W}-40 \mathrm{E})$ averaged changes in Obs and simulations
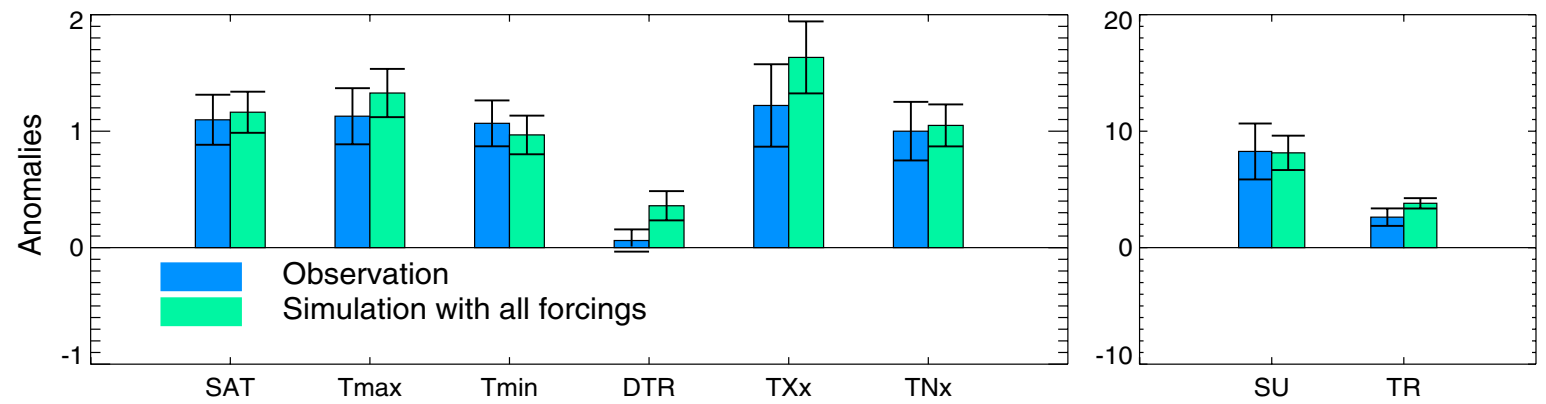

(b) Area averaged changes in response to different forcings
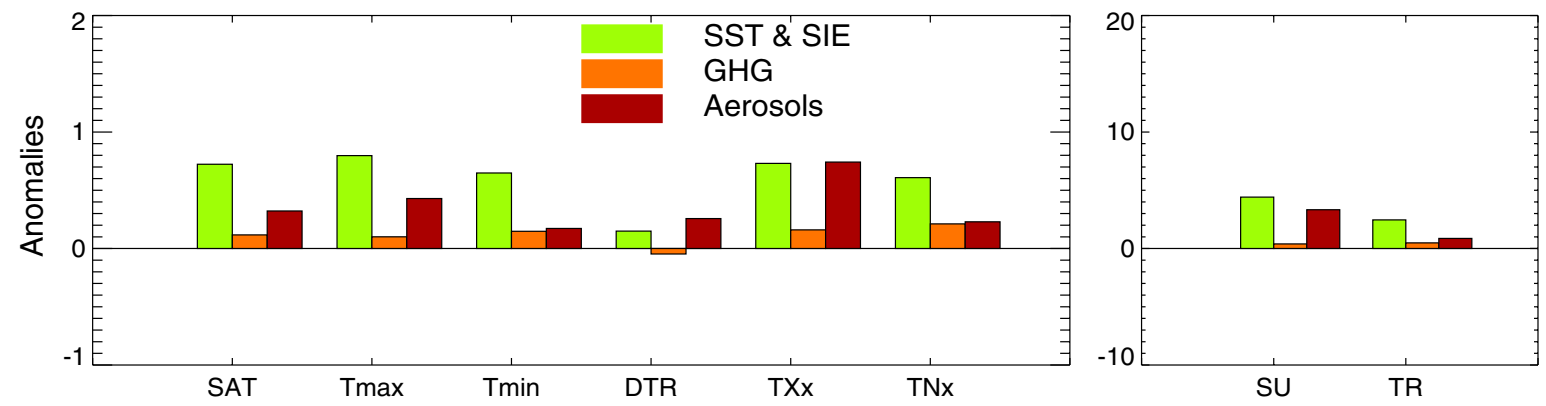

Fig. 9 Observed and model simulated summer seasonal mean (JJA) changes for SAT, $\mathrm{T}_{\max }, \mathrm{T}_{\min }$, and DTR, the annual changes in annual hottest day $\left(\mathrm{TX}_{\mathrm{x}}\right)$ and warmest night $\left(\mathrm{TN}_{\mathrm{x}}\right)$ temperature, frequency of summer days (SU) and tropical nights (TR) averaged over Western Europe. SAT, $\mathrm{T}_{\max }, \mathrm{T}_{\min }, \mathrm{DTR}, \mathrm{TX}_{\mathrm{x}}$, and $\mathrm{TN}_{\mathrm{x}}$ are in ${ }^{\circ} \mathrm{C}$. SU and TR are in day year ${ }^{-1}$. a Observed changes (based on CRUTS3.2 and HadEX2) data sets, and simulated responses to changes in SST/ SIE, GHG concentrations, and AAer precursor emissions (ALL-

2009; Fasullo 2010; Boé and Terray 2014). The decrease of cloud cover leads to positive shortwave cloud radiative effect (SW CRE) and negative longwave (LW) CRE (Fig. 10e, f), and therefore an increase in net surface SW (Fig. 10g). The increase of the surface net SW radiation and clear sky LW radiation over land, only part of which is compensated by net surface longwave cooling (Fig. 10h) related to the negative LW CRE and increased upward turbulent heat flux (Fig. 10i), acts to warm the surface. Note, however, that the small net LW anomaly (Fig. 10h) is likely to reflect a balance between increased absorption of radiation emitted by the warmer and moister atmosphere, increased emission from the warmer surface (Fig. 10b), and LW CRE (Fig. 10f). The role of reduced cloud cover on warming over Eastern Europe is in line with the study of Tang et al. (2012) who highlighted the role of decreases in cloud for European hot summers in observations. Our study further suggests that the decrease in summer cloud cover over Europe during the recent decades might be partially due to changes in SST/SIE. The decrease in cloud cover is in turn also partly responsible for increases in $\mathrm{T}_{\max }, \mathrm{TX}_{\mathrm{x}}$, and the frequency in summer days (Fig. 9b).
CONTROL). The coloured bars indicated the central estimates and the whiskers show the $90 \%$ confidence intervals based on a two tailed Student $t$ test. b Model simulated changes in response to different forcings. SST \& SIE is the response to changes in SST/SIE (SSTONLY-CONTROL). GHG is the response to GHG concentrations (SSTGHG-SSTONLY), and Aerosols is the response to changes in AAer precursor emissions (ALL-SSTGHG)

\subsection{Response to the direct impact of changes in GHGs forcing}

The spatial patterns of summer mean changes for the components of surface energy balance and related variables induced by changes in GHG forcing are illustrated in Fig. 11. The primary surface energy change over Europe is an increase in the net surface LW radiation (Fig. 11a), partly due to the increase in downward surface LW radiation (as expected for an enhanced Greenhouse Effect) and partly due to LW feedback related to the increase in water vapour (Fig. 11b). The cloud cover changes show a dipole structure with a decrease over Northern Europe and an increase over Southern Europe (Fig. 11c), consistent with the dipole pattern of changes in relative humidity (Fig. 11d), precipitation and soil moisture (Fig. 11e, f). The complex patterns of changes in relative humidity, cloud cover, precipitation and soil moisture reflect the impact of GHG induced changes in circulation over the North Atlantic and European sector that is characterized by anomalous high SLP over high latitude and anomalous low SLP to south over Southern Europe (not shown). The dipole 
(a) Water vapor in JJA (SST)

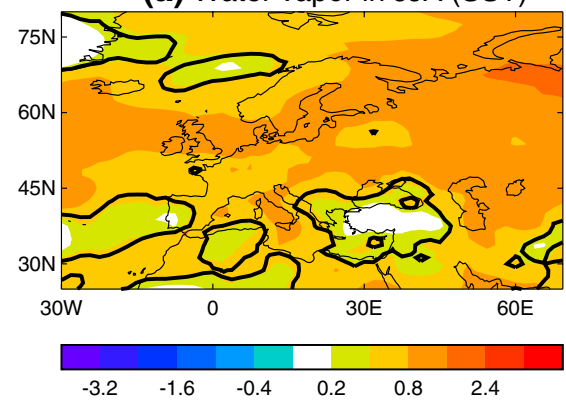

(d) Total cloud in JJA (SST)

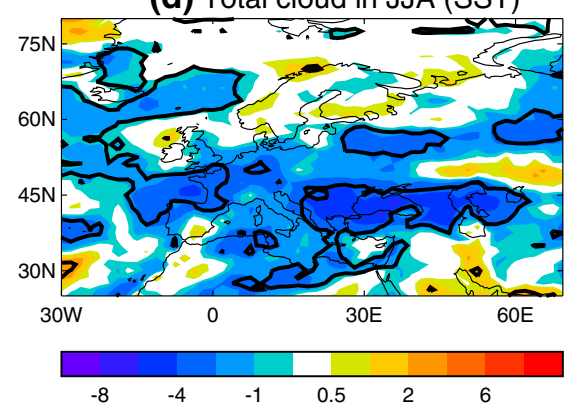

(g) SW in JJA (SST)

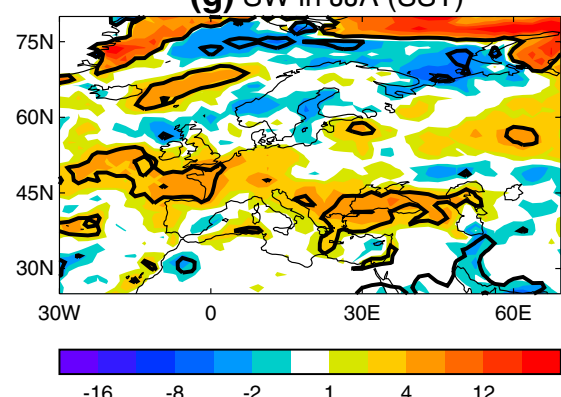

(b) clear sky LW in JJA (SST)

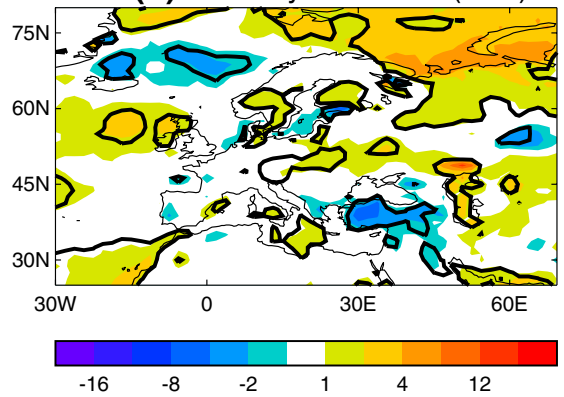

(e) SW CRE in JJA (SST)

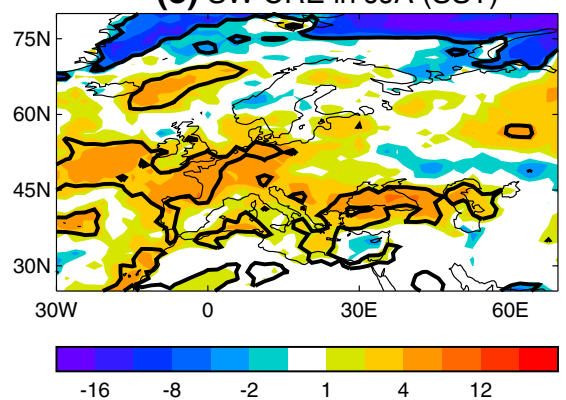

(h) LW in JJA (SST)

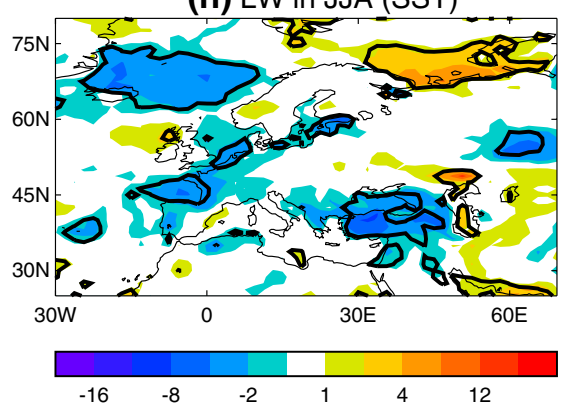

(c) $700 \mathrm{hPa} \mathrm{RH}$ in JJA (SST)

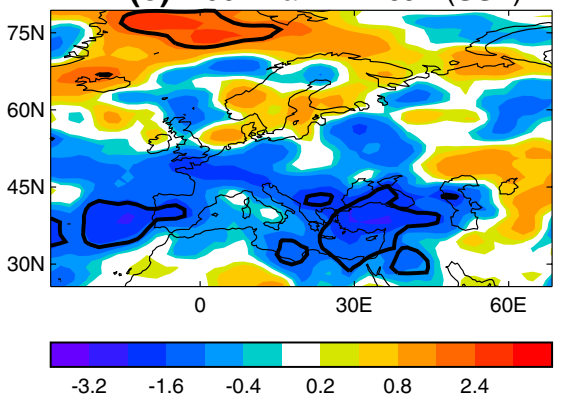

(f) LW CRE in JJA (SST)

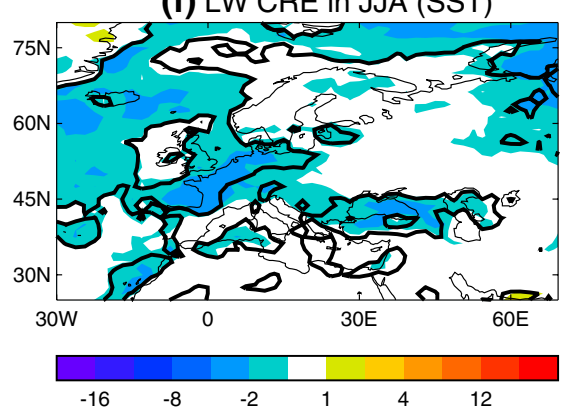

(i) LH \& SH in JJA (SST)

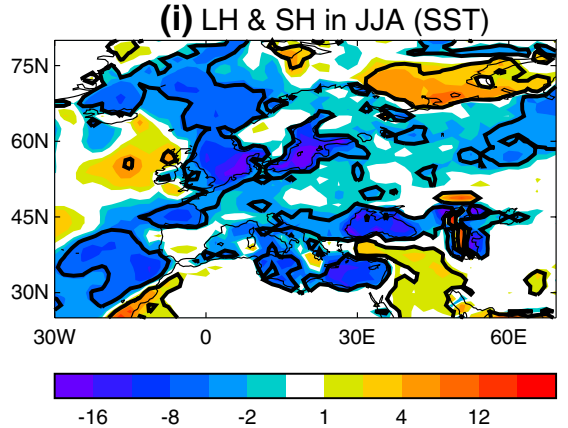

Fig. 10 Spatial patterns of responses to changes in SST/SIE (SSTONLY-CONTROL). a Column integrated water vapor $\left(\mathrm{kg} \mathrm{m}^{-2}\right)$, b clear sky surface LW, c $700 \mathrm{hPa}$ relative humidity (RH, \%), d Total cloud cover (\%), e SW CRE, f LW CRE, $\mathbf{g}$ surface SW, h surface LW, and $\mathbf{i}$ surface turbulent heat flux. Radiation and fluxes are in $\mathrm{W} \mathrm{m}^{-2}$ and positive values mean downward. Radiation is the net component. Thick black lines highlight regions where the changes are statistically significant at the $90 \%$ confidence level using a two-tailed Student $t$ test

by changes in AAer are illustrated in Fig. 12. Changes in sulphate aerosol optical depth (AOD) (Fig. 12a) show a decrease of $\sim 0.2-0.4$ over Western Europe which is about $40-80 \%$ decrease relative to the simulation for the period 1964-1993. The magnitude of the decrease in model simulated sulphate AOD is similar to observed changes from six locations over Europe (Ruckstuhl et al. 2008).

The decrease in AAer precursor emissions over Europe induces a significant local warming through aerosol-radiation and aerosol-cloud interactions (e.g., Twomey 1977; Rosenfeld et al. 2008; Nabat et al. 2014; Dong et al. 2015). Changes in surface energy budget are characterized by large increase in the net SW over Europe (Fig. 12b). Cloud cover changes show a large decrease over Central and Southern Europe (Fig. 12f)
The spatial patterns of summer mean changes for the components of surface energy balance and related variables induced

\subsection{Response to the direct impact of changes in AAer precursor emissions}


(a) LW in JJA (GHG)

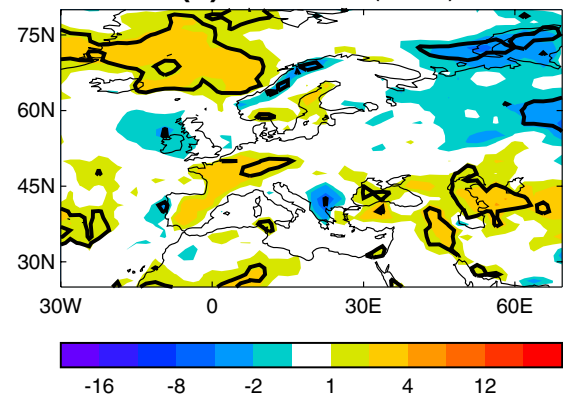

(d) $700 \mathrm{hPa} \mathrm{RH}$ in JJA (GHG)

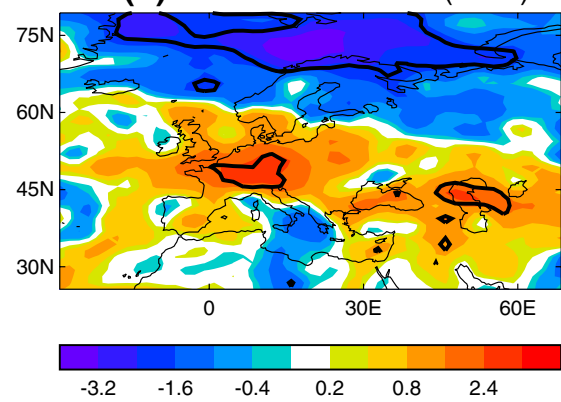

(g) SW CRE in JJA (GHG)

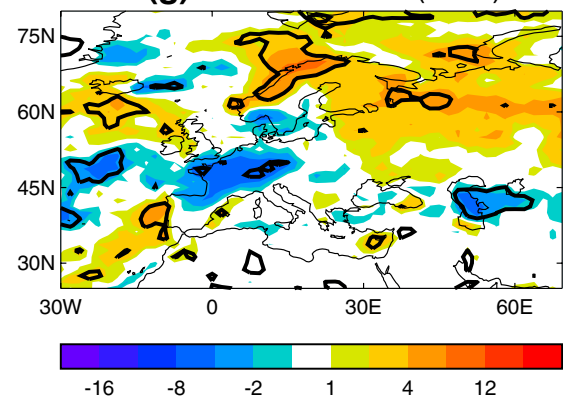

(b) Water vapor in JJA (GHG)

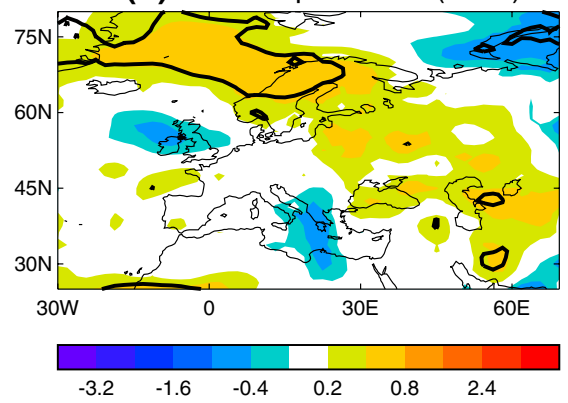

(e) $\operatorname{Pr}$ in JJA (GHG)

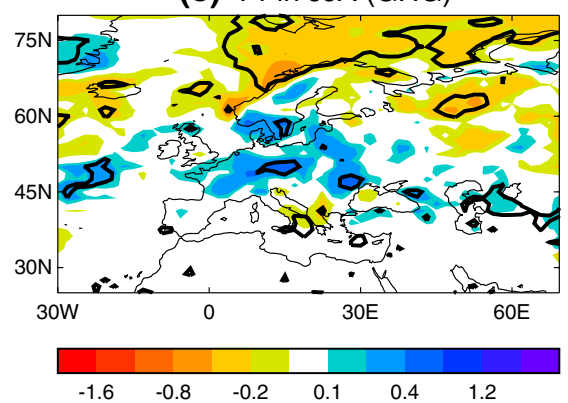

(h) LW CRE in JJA (GHG)

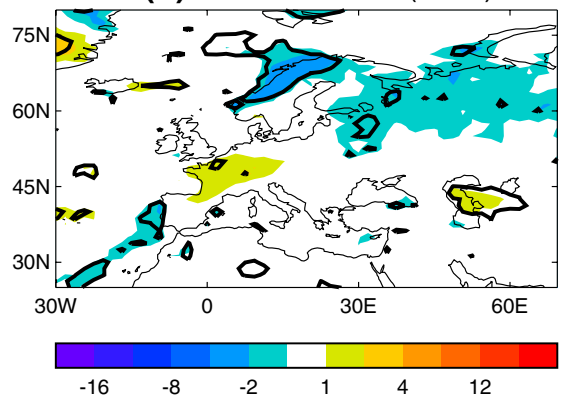

(c) Total cloud in JJA (GHG)

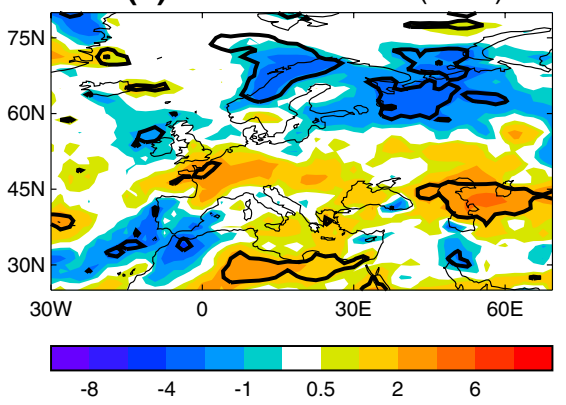

(f) Soil moisture in JJA (GHG)

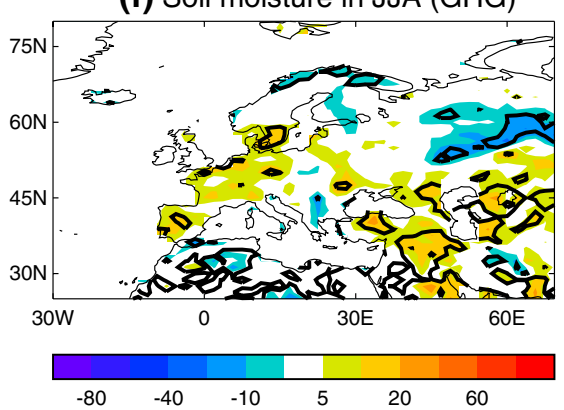

(i) SW in JJA (GHG)

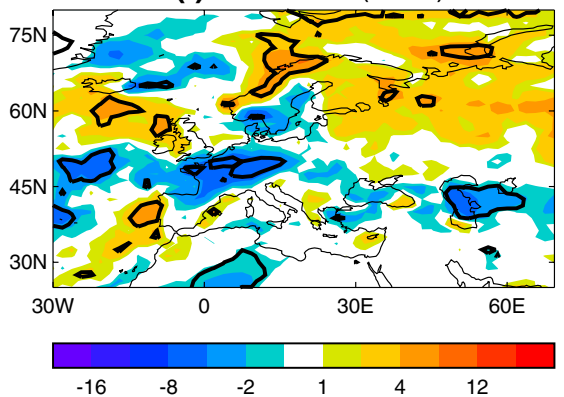

Fig. 11 Spatial patterns of responses to changes in GHG forcing (SSTGHG-SSTONLY). a Surface LW, b column integrated water vapor $\left(\mathrm{kg} \mathrm{m}^{-2}\right)$, c total cloud cover (\%), d $700 \mathrm{hPa} \mathrm{RH} \mathrm{( \% ),} \mathrm{e} \mathrm{precipi-}$ tation $\left(\mathrm{mm} \mathrm{day}^{-1}\right), \mathbf{f}$ soil moisture $\left(\mathrm{kg} \mathrm{m}^{-2}\right)$, g SW CRE, h LW CRE,

with an increase to the north, consistent with the changes in soil moisture over Europe (Fig. 12i). The decrease in cloud cover gives rise to positive SW CRE of $2-6 \mathrm{~W} \mathrm{~m}^{-2}$ and negative LW CRE of $2-4 \mathrm{~W} \mathrm{~m}^{-2}$ (Fig. 12h, i). These lead to larger changes in the net $\mathrm{SW}$ of about $8-16 \mathrm{~W} \mathrm{~m}^{-2}$ and $\mathrm{LW}$ of about 4-8 $\mathrm{W} \mathrm{m}^{-2}$ (Fig. 12b, c) than change in the clear sky net SW of about 6-8 and LW at the surface (not shown). The increase in clear sky SW at the surface is about 2-3 times as large as the increase in SW CRE (Fig. 12b, g), indicating the dominant role of aerosol-radiation interaction in the surface solar radiation change over Western Europe. This is in line with Ruckstuhl et al. (2010) who found a small contribution of cloud impact to the recent solar brightening over Europe. The increase in surface net SW and the decrease in upward latent heat flux (Fig. 12d) due to soil drying (Fig. 12i) over Southern Europe and $\mathbf{i}$ surface SW. Radiation and fluxes are in $\mathrm{W} \mathrm{m}^{-2}$ and positive values mean downward. Radiation is the net component. Thick black lines highlight regions where the changes are statistically significant at the $90 \%$ confidence level using a two-tailed Student $t$ test

give rise to large warming in surface air temperature over Western Europe and large changes in temperature extremes.

These results further suggest that decreased AAer precursor emissions over Europe might also play an important role for the decrease in summer cloud cover during the recent decades over Europe (e.g., Tang et al. 2012) in which the deficit of soil moisture limits evapotranspiration, which results in an increased upward sensible heat fluxes (Fig. 12e) due to the energy conservation constraint. The shift towards higher sensible heat fluxes in turn produces drier and warmer air and increases evaporative demand, which dries the soil further (Mueller and Seneviratne 2012; Boé and Terray 2014; Miralles et al. 2014; Cattiaux et al. 2015; Whan et al. 2015). This positive feedback loop generates less cloud and increased surface SW radiation, which again causes even 
(a) Sulphate AOD at 0.55 um in JJA (aerosols)

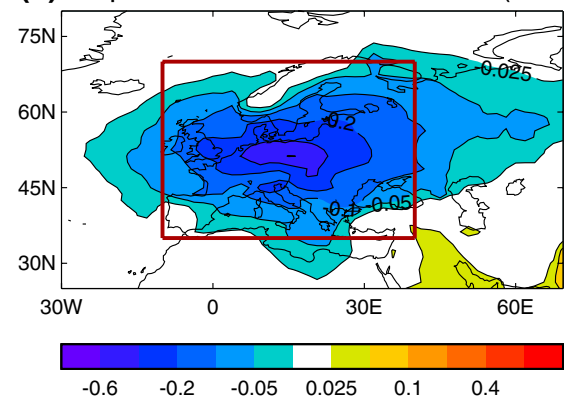

(d) LH in JJA (aerosols)

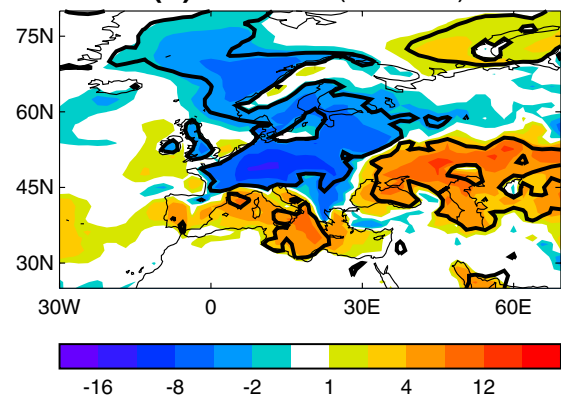

(g) CRE SW in JJA (aerosols)

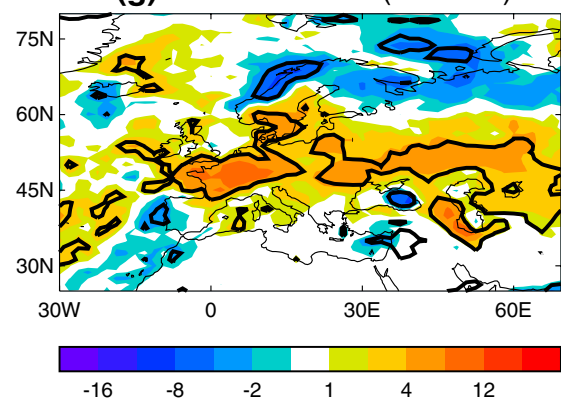

(b) SW in JJA (aerosols)

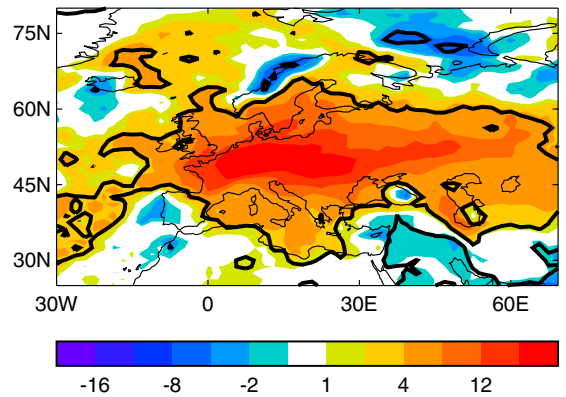

(e) SH in JJA (aerosols)

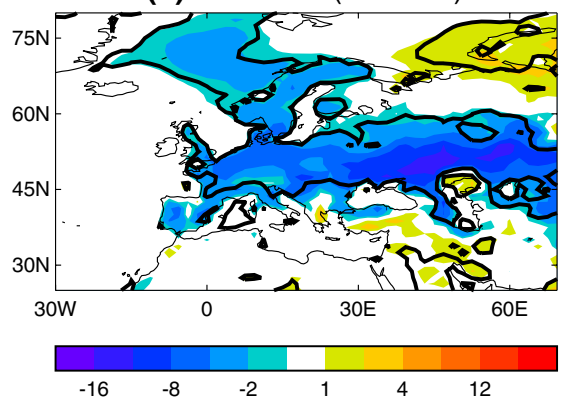

(h) CRE LW in JJA (aerosols)

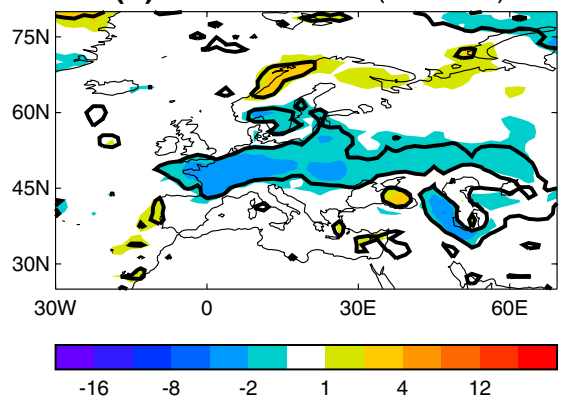

(c) LW in JJA (aerosols)

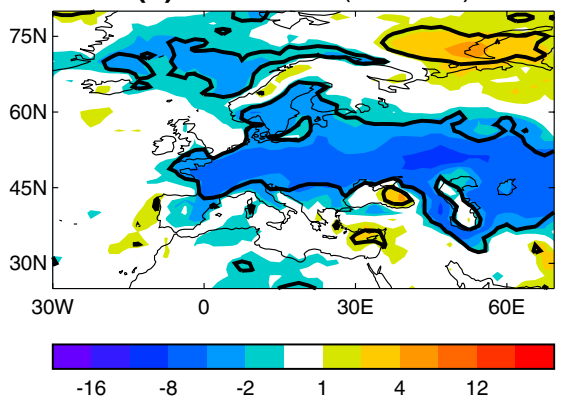

(f) total cloud in JJA (aerosols)

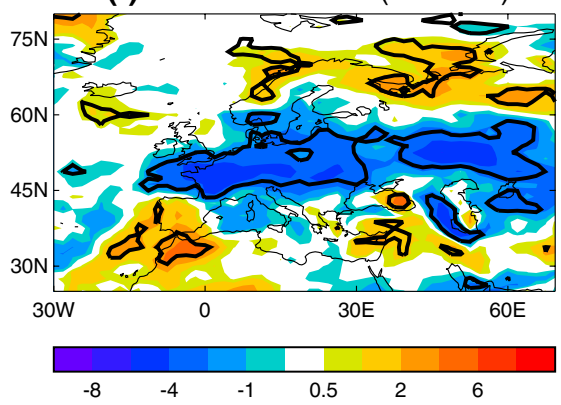

(i) Soil moisture in JJA (aerosols)

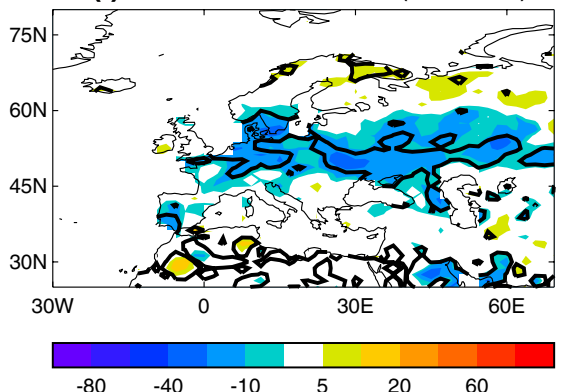

Fig. 12 Spatial patterns of responses to AAer changes (ALL-SSTGHG). a Sulphate AOD at $0.55 \mu \mathrm{m}$, b surface SW, c surface LW, d surface latent heat flux, e sensible heat flux, $\mathbf{f}$ total cloud cover (\%), g SW CRE, $\mathbf{h}$ LW CRE, and $\mathbf{i}$ soil moisture $\left(\mathrm{kg} \mathrm{m}^{-2}\right)$. Radiation and fluxes are in $\mathrm{W} \mathrm{m}^{-2}$ and positive values mean downward. Radiation is the net component. Thick black lines highlight regions where the changes are statistically significant at the $90 \%$ confidence level using a two-tailed Student $t$ test. Thick red box in (a) highlights Western Europe

Europe is mainly the outcome of reduced precipitation in summer, rather than any pre-summer signals, and that the impact of pre-summer land surface conditions on summer surface temperature and temperature extremes in our model simulation is weak. Therefore, three factors in response to AAer changes in the recent decade cause elevated summer SAT and change in temperature extremes: (1) increased solar radiation reaching the surface because of aerosols-radiation interaction due to the reduction of AAer precursor emissions, (2) further enhanced surface solar radiation by the reduction in cloud cover through aerosol-cloud interaction (e.g., Twomey 1977; Rosenfeld et al. 2008), and land-atmosphere interaction (e.g., Zampieri et al. 2009; Jaeger and Seneviratne 2011; Mueller and Seneviratne 2012; Stegehuis et al. 
Fig. 13 Schematic diagram illustrating the major processes of the responses in temperature and temperature extremes over Western Europe to different forcings. In response to AAer changes, the increase in clear sky SW at the surface is about 2-3 times as large as the increase in SW CRE
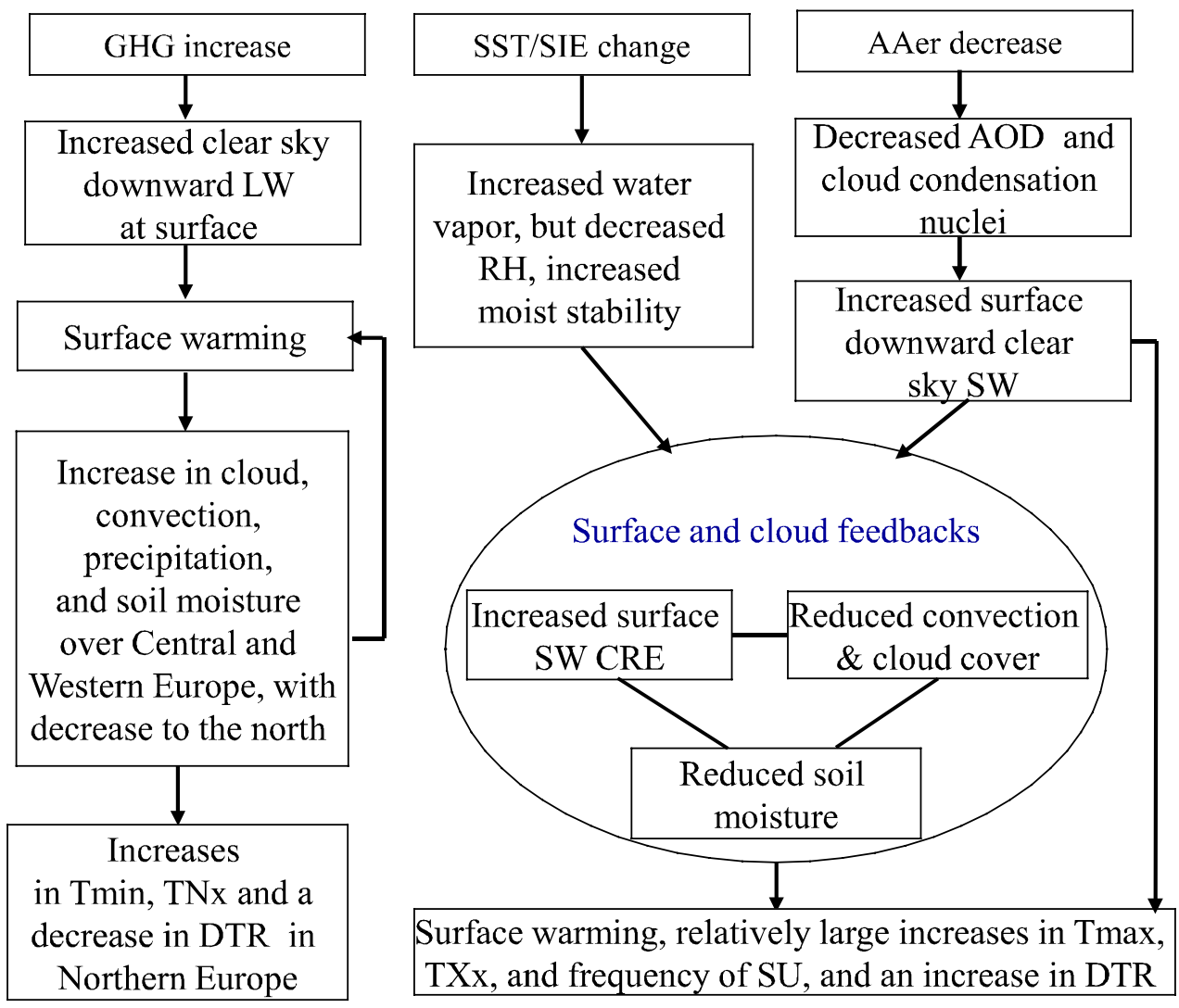

in shaping the changes in the summer mean SAT and temperature extremes. No attempt has yet been made to separate the anthropogenic contribution to SST/SIE change. The main findings are summarized below and the major processes of the responses in temperature and temperature extremes over Western Europe to different forcings are summarized schematically in Fig. 13. The response to the increase in GHGs is mainly related to direct impact on clear sky downward longwave radiation and associated cloud and surface feedbacks. In response to changes in SST/SIE, it is the increased water vapour over Western Europe that leads to surface warming with positive surface and cloud feedbacks resulted from surface drying and the reduction in cloud cover. The response to AAer changes is mainly through aerosol-radiation interaction with additional contributions from aerosol-cloud interaction and coupled atmosphere-land surface feedbacks.

- The analysis of observations indicates that there was a rapid increase in summer mean surface air temperature since the mid-1990s over Western Europe. The area averaged summer mean SAT change over the region during the period $1996-2011$ increased by 0.93 to $1.10{ }^{\circ} \mathrm{C}$ relative to the period 1964-1993 for the four surface temperature data sets.

- Accompanied by this rapid summer mean surface warming are rapid changes in temperature extremes. The 
changes in temperature extremes are characterized by a rapid increase in summer mean $\mathrm{T}_{\max }, \mathrm{T}_{\min }, \mathrm{TX}_{\mathrm{x}}\left(1.2^{\circ} \mathrm{C}\right)$ and $\mathrm{TN}_{\mathrm{x}}\left(1.0^{\circ} \mathrm{C}\right)$. The change in DTR is small. Observations also show a rapid increase in frequency of summer days and tropical nights by 8 and 3 days respectively.

- The HadGEM3A model response to changes in SST/SIE, anthropogenic GHG, and AAer forcings reproduce many of observed changes in summer mean SAT and temperature extremes over Western Europe. The area averaged changes in SAT $\left(1.16^{\circ} \mathrm{C}\right)$ and temperature extremes are quantitatively similar to observed changes except that the model overestimates the increase in DTR (Fig. 9a).

- Responses to different forcing factors indicate a significant role for the direct impact (in addition to an impact via SST/SIE changes) of changes in anthropogenic forcings, especially aerosols, in the rapid warming of European summer temperatures. The drying of the land surface and reduction of cloud cover exert important positive feedbacks. Changes in SST/SIE explain 62.2 $\pm 13.0 \%$ of the area averaged seasonal mean warming signal over Western Europe, with the remaining $37.8 \pm 13.6 \%$ signal explained by the direct impact of changes in anthropogenic GHGs and AAer.

- The direct impact of changes in AAer is a key factor for the increases in $\mathrm{TX}_{\mathrm{x}}$ and frequency of summer days. It explains $45.5 \pm 17.6 \%$ and $40.9 \pm 18.4 \%$ of area averaged signals for these temperature extremes.

- The direct impact of AAer changes act to increase DTR, but change in DTR is countered by direct impact of GHG forcing.

Whilst each forcing factor causes summer mean surface warming and associated temperature extreme changes over Western Europe, the spatial patterns of responses and physical processes are distinct in each case (Fig. 13). For example, SST/SIE changes lead to more or less uniform summer mean warming at the surface. In contrast, changes in AAer lead to a band of surface warming and temperature extreme changes in latitude of $40^{\circ} \mathrm{N}-55^{\circ} \mathrm{N}$. AAer changes also lead to an increase in summer blocking frequency by $18 \%$ (Figure not shown), which in turn may have an impact on surface warming and increases in temperature extremes. The results in this study illustrate the important role of the direct impact of changes in AAer not only on summer mean temperature but also on temperature extremes. Reduction of AAer precursor emissions not only induces increased downward solar radiation through aerosol-radiation and aerosol-cloud interactions, but also induces local positive feedbacks between surface warming and reduced cloud cover, increased blocking frequency, reduced precipitation, soil moisture, and evaporation (Fig. 13). These changes occur on very short time scales of weeks (e.g., Dong et al. 2015) and are important processes leading to the local increases in DTR, $\mathrm{TX}_{\mathrm{x}}$, and frequency of summer days (Fig. 13). The change in cloud, in turn, is closely related to the change in the hydrological cycle.

In the next few decades, greenhouse gas concentrations will continue to rise and anthropogenic aerosol precursor emissions over Europe and North America will continue to decline. Our results suggest that the changes in seasonal mean SAT and temperature extremes over Western Europe since the mid-1990s are most likely to be sustained or amplified in the near term, unless other factors intervene.

Acknowledgments This work was supported by EUCLEIA project funded by the European Union's Seventh Framework Programme [FP7/2007-2013] under Grant Agreement No. 607085. BD, RTS, and LS are supported by the U.K. National Centre for Atmospheric Science-Climate (NCAS-Climate) at the University of Reading. UD, GPCP, GISTEMP, NCEP/NCAR reanalysis is provided by the NOAA/OAR/ESRL PSD, Boulder, Colorado, USA, from their Web site at http://www.esrl.noaa.gov/psd/. CRUTS3.21 data are available from the British Atmospheric Data Centre from the site http://badc. nerc.ac.uk/browse/badc/cru/data/cru_ts/cru_ts_3.21/data/. HadISST, HadSLP2, and HadCRUT4 data sets are available from http://www. metoffice.gov.uk/hadobs/. E-OBS gridded data set is available from http://www.ecad.eu/download/ensembles/ensembles.php. Authors would like to thank Laura Wilcox for comments and suggestions on the early version of the paper. The authors would also like to thank two anonymous reviewers for their constructive comments and suggestions on the paper.

Open Access This article is distributed under the terms of the Creative Commons Attribution 4.0 International License (http://creativecommons.org/licenses/by/4.0/), which permits unrestricted use, distribution, and reproduction in any medium, provided you give appropriate credit to the original author(s) and the source, provide a link to the Creative Commons license, and indicate if changes were made.

\section{References}

Adler RF, Huffman GF, Chang A, Ferraro R, Xie P, Janowiak J, Rudolf B, Schneider U, Curtis S, Bolvin D, Gruber A, Susskind J, Arkin P, Nelkin E (2003) The version 2 global precipitation climatology project (GPCP) monthly precipitation analysis (1979-present). J Hydrometeorol 4:1147-1167

Allan R, Ansell T (2006) A new globally complete monthly historical gridded mean sea level pressure dataset (HadSLP2): 1850-2004. J Clim 19:5816-5842

Barnes EA, Dunn-Sigouin E, Masato G, Woollings T (2014) Exploring recent trends in Northern Hemisphere blocking. Geophys Res Lett 41:638-644. doi:10.1002/2013GL058745

Barriopedro DE, Fischer M, Luterbacher J, Trigo RM, García-Herrera R (2011) The hot summer of 2010: redrawing the temperature record map of Europe. Science 332:220-224

Bellouin N, Mann GW, Woodhouse MT, Johnson C, Carslaw KS, Dalvi M (2013) Impact of the modal aerosol scheme GLOMAPmode on aerosol forcing in the Hadley Centre Global Environmental Model. Atmos Chem Phys 13:3027-3044. doi:10.5194/ acp-13-3027-2013

Black E, Sutton R (2007) The influence of oceanic conditions on the European summer of 2003. Clim Dyn 28:53-66 
Boé J, Terray L (2014) Land-sea contrast, soil-atmosphere and cloudtemperature interactions: interplays and roles in future summer European climate change. Clim Dyn 42:683-699

Carril AF, Gualdi S, Cherchi A, Navarra A (2008) Heatwaves in Europe: areas of homogeneous variability and links with the regional to large-scale atmospheric and SSTs anomalies. Clim Dyn 30:77-98. doi:10.1007/s00382-007-0274-5

Cassou C, Terray L, Phillips AS (2005) Tropical Atlantic influence on European heat waves. J Clim 18:2805-2811

Cattiaux J, Douville H, Schoetter R, Parey S, Yiou P (2015) Projected increase in diurnal and interdiurnal variations of European summer temperatures. Geophys Res Lett. doi:10.1002/201 4GL062531

Christidis N, Stott PA, Brown SJ (2011) The role of human activity in the recent warming of extremely warm daytime temperatures. J Clim 24:1922-1930

Christidis N, Stott PA, Jones GS, Shiogama H, Nozawa T, Luterbacher L (2012) Human activity and anomalously warm seasons in Europe. Int J Climatol 32:225-239

Christidis N, Stott PA, Hegerl GC, Betts RA (2013) The role of land use change in the recent warming of daily extreme temperatures. Geophys Res Lett 40:589-594

Christidis N, Jones GS, Stott PA (2014) Dramatically increasing chance of extremely hot summers since the 2003 European heatwave. Nat Clim Change. doi:10.1038/NCLIMATE2468

Dai A, Trenberth KE, Karl TR (1999) Effects of clouds, soil moisture, precipitation and water vapor on diurnal temperature range. J Clim 12:2451-2473

Della-Marta PM, Luterbacher J, von Weissenfluh H, Xoplaki E, Brunet M, Wanner H (2007) Summer heat waves over western Europe 1880-2003, their relationship to large-scale forcings and predictability. Clim Dyn 29:251-275

Dole R et al (2011) Was there a basis for anticipating the 2010 Russian heat wave? Geophys Res Lett 38:L06702. doi:10.1029/201 0GL046582

Donat MG et al (2013) Updated analyses of temperature and precipitation extreme indices since the beginning of the twentieth century: the HadEX2 dataset. J Geophys Res Atmos 118:20982118. doi:10.1002/jgrd. 50150

Dong BW, Sutton R (2015) Dominant role of greenhouse gas forcing in the recovery of Sahel rainfall. Nat Clim Change. doi:10.1038/ nclimate 2664

Dong BW, Gregory JM, Sutton RT (2009) Understanding land-sea warming contrast in response to increasing greenhouse gases. Part I: transient adjustment. J Clim 22:3079-3097

Dong BW, Sutton RT, Highwood E, Wilcox L (2015) Preferred response of the East Asian summer monsoon to local and nonlocal anthropogenic sulphur dioxide emissions. Clim Dyn. doi:10.1007/s00382-015-2671-5

Fasullo JT (2010) Robust land-ocean contrasts in energy and water cycle feedbacks. J Climate 23:4677-4693

Feudale L, Shukla J (2011a) Influence of sea surface temperature on the European heat wave of 2003 summer. Part I: an observational study. Clim Dyn 36:1691-1703

Feudale L, Shukla J (2011b) Influence of sea surface temperature on the European heat wave of 2003 summer. Part II: a modeling study. Clim Dyn 36:1705-1715

Fischer EM, Schär C (2010) Consistent geographical patterns of changes in high-impact European heatwaves. Nat Geosci 3:398-403

Fischer EM, Rajczak J, Schär C (2012) Changes in European summer temperature variability revisited. Geophys Res Lett 39:L19702. doi:10.1029/2012GL052730

Folini D, Wild M (2011) Aerosol emissions and dimming/brightening in Europe: sensitivity studies with ECHAM5-HAM. J Geophys Res 116:D21104. doi:10.1029/2011JD016227
Hanlon HM, Morak S, Hegerl GC (2013) Detection and prediction of mean and extreme European summer temperatures with a multimodel ensemble. J Geophys Res (Atmos) 118:9631-9641. doi:10.1002/jgrd.50703

Hansen J, Ruedy R, Sato M, Lo K (2010) Global surface temperature change. Rev Geophys 48:4004. doi:10.1029/2010RG000345

Harris I, Jones PD, Osborn TJ, Lister DH (2014) Updated high-resolution grids of monthly climatic observations-the CRU TS3.10 dataset. Int J Climatol 34:623-642. doi:10.1002/joc.3711

Haylock MR, Hofstra N, Klein Tank AMG, Klok EJ, Jones PD, New M (2008) A European daily high-resolution gridded data set of surface temperature and precipitation for 1950-2006. J Geophys Res 113:D20119. doi:10.1029/2008JD10201

Hegerl G, Luterbacher J, González-Rouco F, Tett SFB, Crowley TJ (2011) Influence of human and natural forcing on European seasonal temperatures. Nat Geosci. doi:10.1038/ NGEO1057

Hewitt HT, Copsey D, Culverwell ID, Harris CM, Hill RSR, Keen AB, McLaren AJ, Hunke EC (2011) Design and implementation of the infrastructure of HadGEM3: the next-generation Met Office climate modelling system. Geosci Model Dev 4:223-253

Hoerling M, Eischeid J, Perlwitz J, Quan X, Zhang T, Pegion P (2012) On the increased frequency of mediterranean drought. J Clim 25:2146-2161

Jaeger EB, Seneviratne SI (2011) Impact of soil moisture-atmosphere coupling on European climate extremes and trends in a regional climate model. Clim Dyn 36:1919-1939

Kalnay E, Kanamitsu M, Kistler R, Collins W, Deaven D, Gandin L, Joseph D (1996) The NCEP/NCAR 40-year reanalysis project. Bull Am Meteor Soc 77:437-471

Kamae Y, Shiogama H, Watanabe M, Kimoto M (2014) Attributing the increase in Northern Hemisphere hot summers since the late 20th century. Geophys Res Lett 41:5192-5199. doi:10.1002/201 4GL061062

Kim OY, Wang B, Shin SH (2013) How do weather characteristics change in a warming climate? Clim Dyn 41:3261-3281. doi:10.1007/s00382-013-1795-8

Kühn T et al (2014) Climate impacts of changing aerosol emissions since 1996. Geophys Res Lett 41:4711-4718. doi:10.1002/201 4GL060349

Lamarque JF et al (2010) Historical (1850-2000) gridded anthropogenic and biomass burning emissions of reactive gases and aerosols: methodology and application. Atmos Chem Phys 10:7017-7039

Legates DR, Willmott CJ (1990a) Mean seasonal and spatial variability global surface air temperature. Theoret Appl Climatol 41:11-21

Legates DR, Willmott CJ (1990b) Mean seasonal and spatial variability in gauge-corrected, global precipitation. Int $\mathbf{J}$ Climatol 10:111-127

Lindvall J, Svensson G (2014) The diurnal temperature range in the CMIP5 models. Clim Dyn. doi:10.1007/s00382-014-2144-2

Miralles DG, Teuling AJ, Van Heerwaarden CC (2014) Mega-heatwave temperatures due to combined soil desiccation and atmospheric heat accumulation. Nat Geosci 7:345-349. doi:10.1038/ ngeo2141

Morice CP, Kennedy JJ, Rayner NA, Jones PD (2012) Quantifying uncertainties in global and regional temperature change using an ensemble of observational estimates: the HadCRUT4 dataset. J Geophys Res 117:D08101. doi:10.1029/2011JD017187

Mueller B, Seneviratne SI (2012) Hot days induced by precipitation deficits at the global scale. Proc Natl Acad Sci 109:12398-12403

Nabat P, Somot S, Mallet M, Sanchez-Lorenzo A, Wild M (2014) Contribution of anthropogenic sulfate aerosols to the changing Euro-Mediterranean climate since 1980. Geophys Res Lett 41:5605-5611. doi:10.1002/2014GL060798 
Otto FE, Massey N, van Oldenborgh GJ, Jones RG, Allen MR (2012) Reconciling two approaches to attribution of the 2010 Russian heat wave. Geophys Res Lett 39:L04702. doi:10.1029/201 $1 \mathrm{GL} 050422$

Perkins SE (2015) A review on the scientific understanding of heatwaves - their measurement, driving mechanisms, and changes at the global scale. Atmos Res 164:242-267

Philipona R, Behrens K, Ruckstuhl C (2009) How declining aerosols and rising greenhouse gases forced rapid warming in Europe since the 1980s. Geophys Res Lett 36:L02806. doi:10.1029/2008GL036350

Rahmstorf S, Coumou D (2011) Increase of extreme events in a warming world. Proc Natl Acad Sci USA 108:17905-17909

Rayner NA, Parker DE, Horton EB, Folland CK, Alexander LV, Rowell DP, Kent EC, Kaplan A (2003) Global analyses of SST, sea ice and night marine air temperature since the late nineteenth century. J Geophys Res. doi:10.1029/2002JD002670

Rosenfeld D et al (2008) Flood or drought: how do aerosols affect precipitation? Science 321:1309-1313. doi:10.1126/ science. 1160606

Rowell DP, Jones RG (2006) Causes and uncertainty of future summer drying over Europe. Clim Dyn 27(2-3):281-299

Ruckstuhl C et al (2008) Aerosol and cloud effects on solar brightening and the recent rapid warming. Geophys Res Lett 35:L12708. doi: 10.1029/2008GL034228

Ruckstuhl C, Norris JR, Philipona R (2010) Is there evidence for an aerosol indirect effect during the recent aerosol optical depth decline in Europe? J Geophys Res 115:D04204. doi:10.1029/2 009JD012867

Schär C, Vidale P, Luthi D, Frei C, Haberli C, Liniger M, Appenzeller $\mathrm{C}$ (2004) The role of increasing temperature variability in European summer heatwaves. Nature 427:332-336

Schubert SD, Wang H, Koster RD, Suarez MJ, Groisman PY (2014) Northern Eurasian heat waves and droughts. J Clim 27:3169-3207

Seneviratne SI, Corti T, Davin EL, Hirschi M, Jaeger EB, Lehner I, Orlowsky B, Teuling AJ (2010) Investigating soil moisture-climate interactions in a changing climate: a review. Earth Sci Rev 99:125-161

Sillmann J, Donat MG, Fyfe JC, Zwiers FW (2014) Observed and simulated temperature extremes during the recent warming hiatus. Environ Res Lett 9:064023. doi:10.1088/1748-9326/9/6/064023

Smith SJ, van Aardenne J, Klimont Z, Andres R, Volke A, Delgado Arias S (2011) Anthropogenic sulfur dioxide emissions:
1850-2005. Atmos Chem Phys 11:1101-1116. doi:10.5194/ acp-11-1101-2011

Stegehuis A, Vautard R, Ciais P, Teuling R, Jung M, Yiou P (2012) Summer temperatures in Europe and land heat fluxes in observation-based data and regional climate model simulations. Clim Dyn. doi:10.1007/s00382-012-1559-x

Stott PA, Stone DA, Allen MR (2004) Human contribution to the European heatwave of 2003. Nature 432:610-644

Sutton RT, Hodson DLR (2005) Atlantic Ocean forcing of North American and European summer climate. Science 309:115-118

Tang Q, Leng G, Groisman PY (2012) European hot summers associated with a reduction of cloudiness. J Clim 25(10):3637-3644. doi:10.1175/JCLI-D-12-00040.1

Trenberth K, Fasullo J (2012) Climate extremes and climate change: the Russian heat wave and other climate extremes of 2010. J Geophys Res 117:D17103. doi:10.1029/2012JD018020

Twomey S (1977) Influence of pollution on shortwave albedo of clouds. J Atmos Sci 34:1149-1152

van Oldenborgh GJ, Drijfhout S, van Ulden A, Haarsma R, Sterl A, Severijns C, Hazeleger W, Dijkstra H (2009) Western Europe is warming much faster than expected. Clim Past 5(1):1-12

Vautard R et al (2007) Summertime European heat and drought waves induced by wintertime mediterranean rainfall deficit. Geophys Res Lett 34:L07711. doi:10.1029/2006GL028001

Vautard R et al (2013) The simulation of European heat waves from an ensemble of regional climate models within the EUROCORDEX project. Clim Dyn 41:2555-2575. doi:10.1007/ s00382-013-1714-z

Vavrus SJ, Notaro M, Lorenz DJ (2015) Interpreting climate model projections of extreme weather events. Weather Clim Extremes 10:10-28

Whan K, Zscheischler J, Orth R et al (2015) Impact of soil moisture on extreme maximum temperatures in Europe. Weather Clim Extrem. doi:10.1016/j.wace.2015.05.001

Wild M (2009) Global dimming and brightening: a review. J Geophys Res 114:D00D16. doi:10.1029/2008JD011470

Wild M (2012) Enlightening global dimming and brightening. Bull Amer Meter Soc 93(1):27-37

Zampieri M, D'Andrea F, Vautard R, Ciais P, De Noblet-Ducoudré N, Yiou P (2009) Hot European summers and the role of soil moisture in the propagation of Mediterranean drought. J Clim 22:4747-4758 